\title{
Multiculturalism in Post-War architecture: Aldo van Eyck and the Otterlo Circles
}

\author{
Alejandro Campos Uribe ${ }^{1} \mid$ María de Miguel Pastor ${ }^{2}$ | Paula Lacomba Montes ${ }^{3}$ | Jordi Martínez Ventura ${ }^{4}$
}

Received: 04-02-2019 | final version: 04-10-2019

Abstract

This research aims to analyse the development of a multiculturalist discourse in European post-war architecture (1950s-1960s). It focuses on the work of the Dutch architect Aldo van Eyck (1918-1999), who built his theoretical framework by merging modern architecture, pre-war avant-garde and the artistic production of non-Western cultures. The Otterlo Circles, presented by Van Eyck during the last CIAM (1959), were an attempt to synthesize a complex design methodology based on a concept of time inherited from James Joyce. After introducing the post-war architectural context of his time, we take the writings of Carola Giedion-Welcker, Van Eyck's mentor in Zurich, as a starting point for a conceptual analysis of his essays. The three official versions of the Otterlo Circles are then presented, suggesting an unofficial fourth version: Van Eyck's house in Loenen aan de Vecht, which will be interpreted as a Collection of experiences-objects-memories. The house and its objects will be used as an initial step to unpack how global travel and art collecting sustained a non-universalist view which gave rise to a profound reconceptualization of architecture. By using the Otterlo Circles, Van Eyck's work appears as the result of a reconciliation of many different cultures, discovered through travels and reading. The keys to understanding his designs are to be found in his house, in the multicultural Collection of objects and strategies he used to build his personal discourse. Following this research, Van Eyck's own house stands out as a necessary place to start any analysis of his work. This research, for the first time, attempts a conceptual explanation of the Otterlo Circles, exploring its theoretical implications for architectural design. Moreover, it develops a novel analysis of his home in Loenen, not only as an architectural project, but as a device intersecting with objects, inhabitants and spatial concepts, a holistic approach to the analysis of domesticity.

Keywords: Domesticity; vernacular art; house in Loenen; Team 10

Citation

Campos Uribe, A. et al. (2020). Multiculturalism in Post-War architecture: Aldo van Eyck and the Otterlo Circles, ACE: Architecture, City and Environment, 14(42), 7033. DOI: http://dx.doi.org/10.5821/ace.14.42.7033

\footnotetext{
1 Department of Architecture, Aalto University, Finland (ORCID: 0000-0002-9382-3481; Researcher ID: $\underline{X-}$ 9466-2019), ${ }^{2}$ Universitat Politècnica de València (ORCID: 0000-0003-1970-502X), ${ }^{3}$ Universitat Politècnica de València (ORCID: 0000-0002-1916-2689; Researcher ID: AAE-2364-2020), ${ }^{4}$ Universitat Politècnica de València (ORCID: 0000-0002-1663-2251; Researcher ID: 0-7035-2016). Contact: alejandro@lcarquitectura.es
} 


\section{Introduction}

In 1959, during what was to be the final CIAM, held in Otterlo (Newman, 1961), the Dutch architect Aldo van Eyck presented his Otterlo Circles, an attempt to graphically synthesize the design method which he developed throughout his career. As a member of the third generation of the Modern Movement, Van Eyck provided a brand new reconceptualization of modern architecture, defending the reconciliation of modern proposals with classic and vernacular traditions. His Circles were designed as a graphic representation of this hybridization. However, when analysing Van Eyck's work, it is worth noting that his discourse takes place in a cultural time of widespread dissatisfaction with modernisation, as represented by the failure of some new neighbourhoods built following the First World War, as well as by the increasing attention to the artistic and architectural production of nonWestern cultures.

While in the interwar period industrialisation found an ideal context for development, the Western population's higher economic level and wellbeing in the 1950s promoted the appearance of new ways of life which favoured more personalised solutions in contrast to excessive standardisation (Risselada \& Van den Heuvel, 2006). The shift is particularly significant in the rejection of the Athens Charter and the introduction to CIAM of new holistic and context-dependant ideas such as the habitat. The members of CIAM at the Sigtuna meeting (1952) were unable to define precisely what they meant by habitat, however, they generally agreed that it referred to an environment that could accommodate the total and harmonious spiritual, intellectual, and physical fulfilment of its inhabitants. According to Candilis, the very use of the term habitat represented an important change in thinking within CIAM, which would develop over the course of the next congresses to represent a set of values that the younger members associated with: a more humane approach to modern architecture (Risselada \& van den Heuvel, 2006).

Alongside this rejection of standardisation and the separation of functions of the early CIAMs, the new frameworks for analysis of the vernacular derived from major anthropological texts. These included Lévi-Strauss's Tristes Tropiques and Marcel Griaule's Die d'eau, which greatly influenced post-war architecture through media such as the surrealist magazine Minotaure. Interest in vernacular cultures in the field of architecture was indeed to be a feature of the post-war period. Following the $6^{\text {th }}$ CIAM, and especially after the $9^{\text {th }}$ CIAM in Aix-en-Provence (1953), this trend is visible in the exhibitions and projects of Bodiansky, Candilis and Woods, Bernard Rudofsky, Ernesto N. Rogers, or Hassan Fathy, together with many others including several CIAM groups, such as ASCORAL and GAMMA. As we will explain, this is also a feature of Van Eyck's work.

\subsection{The Team 10 and the last CIAM 59'}

This socio-cultural context saw the emergence of new values for Modern architecture, driven by the younger CIAM members, a group of architects later known as Team 10. The birth of Team 10 and the 'death' of CIAM has been analysed in depth by Annie Pedret in CIAM and the emergence of Team 10 Thinking, 1945-1959 (2001). Aldo van Eyck was one of the seven most active participants, who along with Jaap Bakema, Georges Candilis, Giancarlo De Carlo, Alison and Peter Smithson, and Shadrach Woods, formed the Core Group (Risselada and Van den Heuvel, 2006). The changes in social context led the group to question certain ideas, such as standardised minimum housing or the strict functional

\footnotetext{
${ }^{1}$ The Independence wars of the colonies of the European empires following the Second World War sparked off the interest in non-Western cultures.
}

ACE, 14 (42) CC BY-ND 3.0 ES | UPC Barcelona, Spain | Multiculturalism in Post-War architecture: Aldo van Eyck and the 2

Otterlo Circles. DOI: http://dx.doi.org/10.5821/ace.14.42.7033 
zoning established by the Athens Charter (McCarter, 2018). Fascinated by spontaneous architecture, the Core Group moved towards specific solutions inspired by local society and culture. The concepts introduced by young CIAM members brought about a sharp turn in modern architecture, calling for greater diversity and stronger relationships with climatic, social, economic, and political conditions, hence promoting an architecture which was closely linked to its context. These ideas were already contained in the founding document of Team 10, the Doorn Manifesto (Risselada \& Van den Heuvel, 2006) signed in 1954.

Team 10 owes its name to its work as organizers of CIAM 10, entitled The Habitat: Problem of InterRelationships in Dubrovnik, 1956, the first in which they were officially represented. However, it was in the following and final CIAM congress (held in Otterlo, 1959), which definitively broke away from the previous congresses, where there was even a staged death of CIAM (Figure 1). The heterogeneous nature of Team 10 meant that this group of architects met periodically to discuss architectural projects while not following a single line of thinking. However, the Team's contribution to the postwar architectural discourse should not be underestimated. To this day, many of its proposals still offer the promise of change, moving towards an inclusive architecture which respects its surroundings and is concerned for the use and temporal evolution of spaces - one designed to facilitate a feeling of belonging while building identity (Risselada \& Van den Heuvel, 2006). Given that Aldo van Eyck was one of the two intellectual driving forces of the group (alongside the Smithsons) his thinking must be explored in order to analyse the proposals put forward by Team 10. Moreover, Team 10's contribution to architecture is even more useful within the context of environmental crisis, which once again highlights the need for resilient sustainable architecture, suited to the context and social relationships, which it supports and generates.

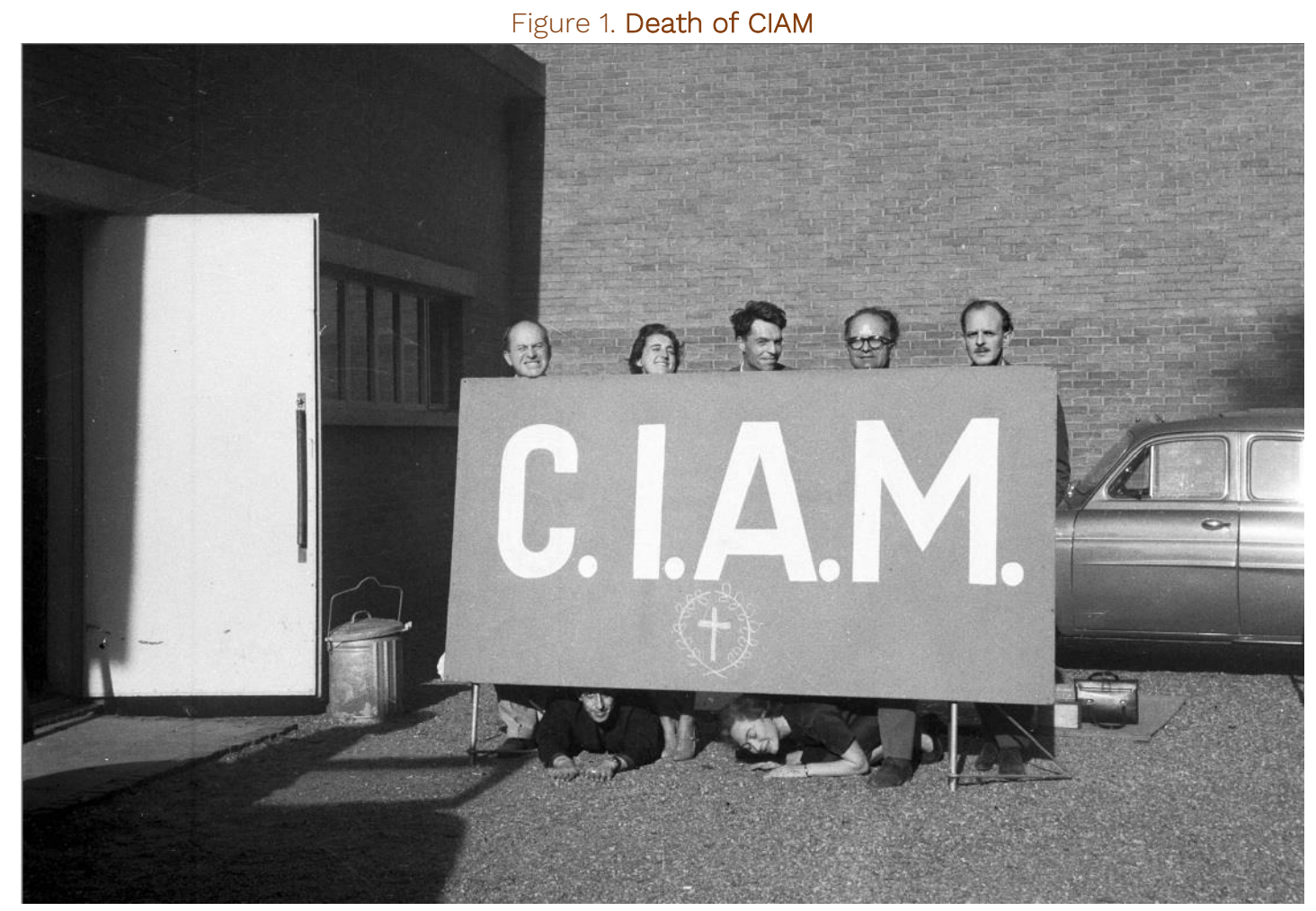

Source: The Aldo and Hannie van Eyck Foundation.

ACE, 14 (42) CC BY-ND 3.0 ES | UPC Barcelona, Spain | Multiculturalism in Post-War architecture: Aldo van Eyck and the 


\subsection{Aldo van Eyck, a multicultural outlook of architecture}

This article aims to explore the theoretical foundations which allowed Van Eyck to reconcile travels, texts, and architectures, from other times and places, in his projects, without resorting to direct copies of formal resources, with no historicism. Van Eyck always located the source of his thinking in the avant-garde. In his opinion, this movement covered several fields of knowledge whose representatives included James Joyce in literature, Arnold Schönberg in music, Henri Bergson in philosophy, and Albert Einstein in science. Together, they made up the Great Gang (Strauven, 1998), as he called them, a group he was introduced to by art critic Carola Giedion-Welcker, whom he had met while studying in Switzerland. It was during his time in Zurich that Van Eyck also came into contact with primitive cultures through his travels and the anthropological texts of Ruth Benedict, Marcel Griaule, Joseph Rykwert and Margaret Mead. Throughout his career he wrote important texts studying non-Western cultures, such as the Dogon or the Pueblo people (Van Eyck, 2008b), texts which were crucial to the development of his own architectural work, presented as an original multicultural proposal.

However, the reconciliation of different cultures proposed by Van Eyck is based on a new idea of time, which makes up the basis of his thinking, continuously repeated in his writings (Van Eyck, 2008a; 2008b). To understand this concept, an initial analysis is needed on how Van Eyck's concepts of time can be identified in James Joyce's novels and are summarised in the three successive versions of the Otterlo Circles. It is also essential to visit the Van Eyck family home in Loenen aan de Vecht, a project completed in 1964 and recently rediscovered and analysed in a doctoral thesis (Campos Uribe, 2018a). His house is the place where all his interests (art, architecture, anthropology...) intersected and created a non-universalist view, which transformed the post-war architectural discourse. His home is in fact the physical incarnation of a final version of the Otterlo Circles, containing an extensive series of sculptures, paintings, books, and different types of objects from different periods.

The new idea of time, in which every instant makes all instants present, can be traced back to the writing and architecture of Van Eyck and those of his literary points of reference, with major implications for how he understands history: "the present should never be understood as the shifting a-dimensional instant between past and future, but as a temporal span experience, shifting in the continuum of consciousness where past and future converge" (Van Eyck, 2008a, p. 74). Combined with relativity, the other core of his thinking, he completely changes our conception of the past, opening our minds not only to the human validity of apparently incompatible solutions developed throughout history, but also to the possibility of recording all this essential meaning in the present. This is why the Otterlo Circles depict a reconciliation of classic tradition, vernacular constructions and modern proposals; a revision of how architectural theory and history must be brought closer together.

While the diagram of the Circles was an abstract representation of how history could be understood - an ideogram -, the architect's house is the specific result of 35 years' worth of travel, discussions, and reading - the accumulation of what Van Eyck collected, learned, and used. This study concludes with a description of the house, aiming to show why, approached as a Collection, it should now be the starting point for the analysis of his thinking. If, as this article is trying to demonstrate, Van Eyck's theoretical contribution to architecture is precisely how he approaches history, reconciling apparently contradictory traditions, then the house, a multicultural collection of learnt projects, is crucial to the analysis of his work.

ACE, 14 (42) CC BY-ND 3.0 ES | UPC Barcelona, Spain | Multiculturalism in Post-War architecture: Aldo van Eyck and the Otterlo Circles. DOI: http://dx.doi.org/10.5821/ace.14.42.7033 


\section{James Joyce, Carola Giedion-Welcker and Aldo Van Eyck}

“Ordovico, Viricordo - Anna was, Livia is, Plurabelle's to be” (Van Eyck, 2008b, p. 131).

This line from Finnegans Wake, James Joyce's final novel, was used by Van Eyck as a greeting only "comprehensible to the initiated" (Van Eyck, 2008b, p. 698)2. In March 1957, he used this line to open his speech introducing Carola Giedion-Welcker at the Amsterdam Stedelijk Museum and to present his concept of time and history, a legacy from Joyce. Historian and art critic, Giedion-Welcker is considered Van Eyck's intellectual mentor. Before they met in Switzerland, the architect's training was essentially literary ${ }^{3}$ but in Zurich, thanks to Giedion-Welcker, Van Eyck became immersed in the modern experience and imbued with the sensitivity which is the consistent basis of his architectural development, a contribution made possible only by the absence of architecture in his initial experiences (Strauven, 1998).

However, why is James Joyce important for understanding Van Eyck's architecture? Why was he so insistent in including him among his references, repeatedly quoting him in his writings? (2008b, pp. 46-47; 131-135; 474-475). Firstly, because Joyce was the perfect link to modernity for someone wellversed in literature who had first read the classic English poets - Swinburne, Blake, Wordsworth, Shakespeare, Lord Byron - and later also Baudelaire, Yeats, Eliot, and Pound. Also because GiedionWelcker considered Joyce a central figure through which to explain the "new reality" or "new consciousness" of avant-garde art, referring to him in many of her writings (Giedion-Welcker, 1928; 1930). Joyce's work can be seen as a framework which feeds Van Eyck's proposals throughout his trajectory, particularly his idea of time, the theoretical foundation of his non-universalist architectural vision.

\subsection{Idea of time in Van Eyck, echoes of Joyce}

"Putting allspace in a notshall" (Giedion-Welcker, 1930, pp. 174-183). Another line from Finnegans Wake, quoted by Giedion-Welcker and Aldo van Eyck, points to a new concept of time, developed and used by Joyce in his novels. The temporal aspect of Joyce's novels is closely related to the proposals of French philosopher Henri Bergson, a useful starting point for unearthing the linguistic mechanisms of Finnegans Wake or Ulysses and for explaining the "interior monologue" (stream of consciousness) technique, a feature of Joycean narrative. Bergson's concepts of duration, involuntary memory or simultaneity quoted by Van Eyck also shed light on his architectural strategies: the space between, the value of history, or the idea of homecoming.

Concisely, Henri Bergson makes the distinction between chronological external time and psychological internal time, a concept found in the idea of duration (durée), introduced in Essai sur les données inmédiates de la conscience (Bergson, 1889). Durée is the word used to refer to internalised psychological time, a present time in which all other time is condensed: past, present and future are not separate but rather form a continuum in our consciousness. In Joyce's novels, places and occasions, objects and human interactions, are presented in a complex and fragmented temporal structure. The interior monologue technique developed by the writer attempts to trace the

\footnotetext{
2 In relation with Giambattista Vico's system, Ordovico means history as a cyclical process where situations and archetypes are recurring. Viricordo is a sort of synthesis of ideas: it combines Giambattista Vico with the idea of return (ricorso), with the idea of memory (ricordo). 'Anna, Livia, Plurabelle' refers to the river Liffey, which runs through Dublin and takes different forms (Plurabelle). In Joyce's novel Anna Livia Plurabelle is the mother, woman and river who represents all women and rivers.

${ }^{3}$ Aldo van Eyck's father, Pieter Nicolaas van Eyck (1887-1954), was a Dutch poet, critic, essayist and philosopher.
}

ACE, 14 (42) CC BY-ND 3.0 ES | UPC Barcelona, Spain | Multiculturalism in Post-War architecture: Aldo van Eyck and the 
durée, the flow of memories, desires, impressions and dreams, as they gradually appear in the consciousness of his characters, mixed and in layers, rather than divided by the verbal tenses of conventional narration. Objects and places acquire meaning through association and tend to reappear throughout the novel (D. E. Clarke, 1985).

Equally, the concept of time in Van Eyck is related to these modern developments and suggests that the subjective time we live in (surrounded by memories and aspirations) is more useful architecturally than an objective and independent time which passes inexorably ${ }^{4}$. Internalised time, Bergson's durée, served as the basis of the concepts of place and occasion coined by Van Eyck, updating the abstract concepts of space and time. Using Joyce's novels as a starting point, through Giedion-Welcker, Van Eyck considers the perception of space rather than the space itself, so that this space is internalised by its inhabitants and incorporated into their body of experiences to become part of a network of places and occasions, a way to relate with the world. Place and occasion are space and time that have been assimilated into the consciousness, relating to other spaces and other times, while the inbetween space becomes an architectural device, which can establish a relation between spaces, promoting a narrative experience of buildings or cities. As we will see, Van Eyck himself constantly resorted to Joyce to explain his work.

It is logical to question the need for such complex mechanisms. Van Eyck and Joyce sought new forms of validity in an attempt to establish some degree of human significance in a relativist context. This need involves the development of a new concept of space (place) and especially of time (occasion), central elements of both Van Eyck and Joyce's thinking. Both seek to attain essential human meaning despite the different colours taken on by reality under changing perspectives, in order to overcome the difficulties created by the loss of absolute concepts ${ }^{5}$. While the narration of Ulysses is the description of the character's duration (not the events but how they appear in consciousness), Van Eyck's architecture is the construction of a place for the inhabitants' duration, a space full of devices on which to anchor and build a narrative experience. Van Eyck proposes a heterogeneous space, broken up into corners designated for different occasions, devised from Joyce and Bergson's mechanisms of perception of consciousness: "provide an in-between realm by means of construction, i.e. to provide, from house to city scale, a bunch of real places for real people and real things" (Van Eyck, 2008a, pp. 54-55). Places which activate the associative mechanisms of consciousness, not space, but the perception of it.

Thus, Aldo van Eyck, starting from a critique of functionalism for producing a loss in human terms, highlights the potential of this new sensitivity to establish architecture as something valuable beyond its mere function. Joyce helps us to understand the new idea of time defended by Van Eyck, and closely linked to Henri Bergson's philosophy (durée). With this as a starting point, the notion of history immediately becomes nuanced.

\subsection{Towards a new idea of history}

In the architecture of Aldo van Eyck, the concept of time can be explored from three perspectives: time in the consciousness of those who visit the work - the perception of space; time as a constituting factor of the work - the natural cycles; and time as the past - history of architecture.

\footnotetext{
${ }^{4}$ In his projects, this interest in a full time takes form in different architectural concepts: labyrinthine clarity (which grows over time by the repetition of the experience), phenomenological transparency (which attempts to interrupt space visually to force anticipation and memory), and other associative mechanisms.

${ }^{5}$ Alongside $\mathrm{H}$. Bergson and J. Joyce, Van Eyck cites Einstein and his relativity: time as a relative dimension.
}

ACE, 14 (42) CC BY-ND 3.0 ES | UPC Barcelona, Spain | Multiculturalism in Post-War architecture: Aldo van Eyck and the 
As explained above, time in those who visit the work refers to the concepts of place and occasion, based on Bergson's durée. For Van Eyck, architecture happens inside consciousness, in a time which becomes occasion when developed in a place, a space which becomes a place in which to build identity. Thus, the references hidden in his buildings are designed as triggers for association (identifying devices). For instance, in the Sonsbeek pavilion (Figure 2), sculptures act as anchorage points articulating the route between walls of concrete blocks. Visitors acquainted with art will be able to detect some of the relationships, which Van Eyck put into place, but others will need to find the key to the place, moving from artwork to artwork, following a strictly personal and autonomous path, forced to interpret a maze of fragments, deliberately complex and without a single established route. Internalised time and space, place and occasion, lead to an architecture which is only articulated by the presence of the inhabitant, inevitably producing a different building for each individual. "As many Londons as there are Londoners" (Van Eyck, 2008a, p. 195).

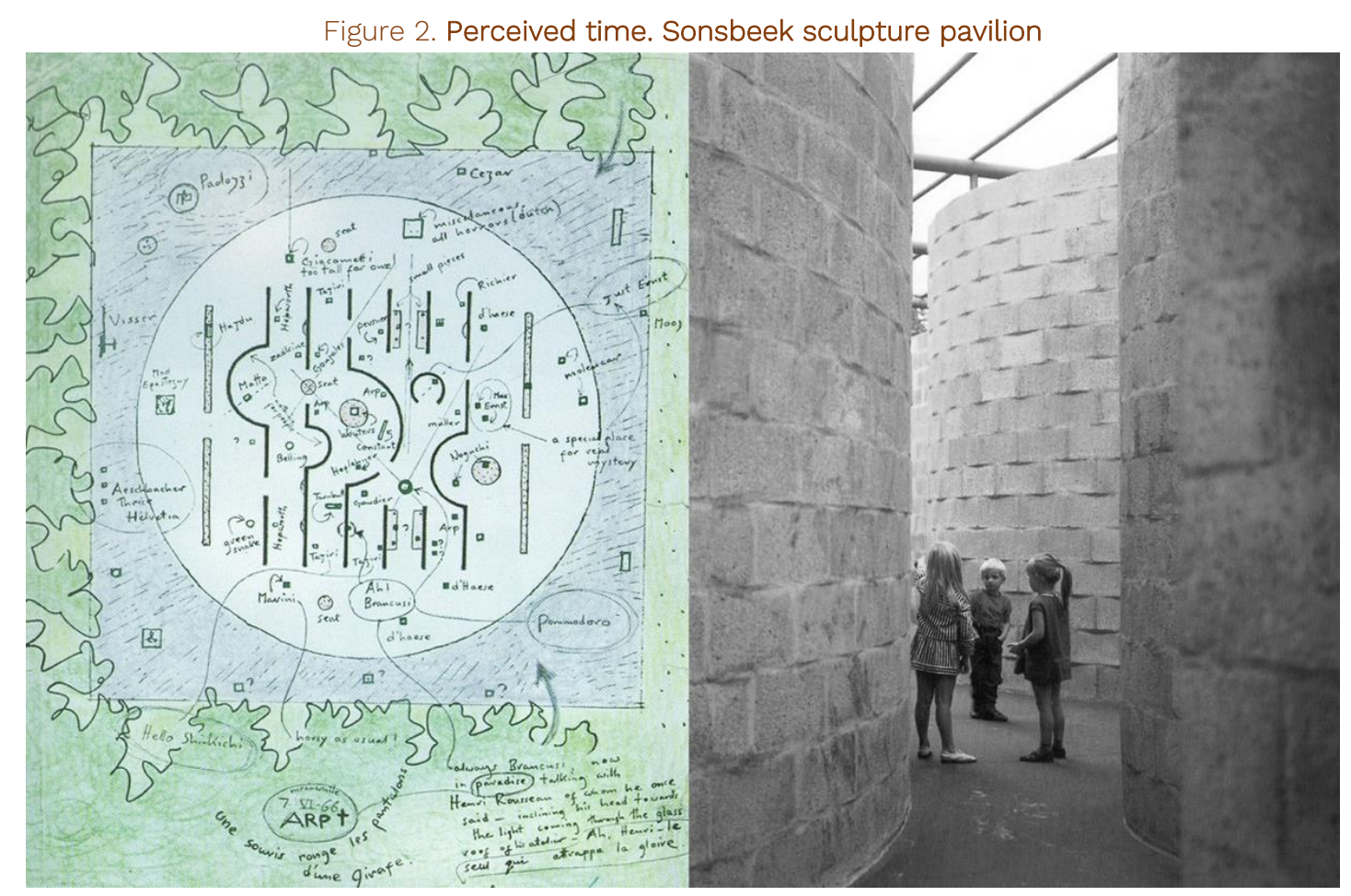

Source: The Aldo and Hannie van Eyck Foundation.

Time as constitutive of the work falls outside the scope of this text, and is manifested in the concepts of cycle and multi-meaning, analysed in depth by D. E. Clarke in pages 160-172 of his doctoral thesis on Van Eyck's thinking (1985). Time creates the work through the accumulation - in material form of the responses to the different times of life and nature: sun or rain, childhood or old age, night or day. This is why the play elements designed for Playgrounds, instead of being figurative elements, single-use devices, are elementary forms - tools - which can be used for different purposes and at different times: several times in a single element (Figure 3).

Finally, under the lens of relativity, time as past (Figure 4) transforms history into a translatable experience and shows Van Eyck's interest in the architecture of other times and cultures; the combination column-base-capital of the Amsterdam Orphanage as a translation of the idea of the classical order; or the entrance to Hubertushuis as a clear interest in San Giorgio Maggiore, in Venice. Van Eyck does not shun the past, nor does he conceive history or the world as having a uniform, unidirectional or pyramid-shaped structure. Instead he conceives it as a spiral: an eternally recurring

ACE, 14 (42) CC BY-ND 3.0 ES | UPC Barcelona, Spain | Multiculturalism in Post-War architecture: Aldo van Eyck and the 7 Otterlo Circles. DOI: http://dx.doi.org/10.5821/ace.14.42.7033 
structure like that proposed by Giambattista Vico in his philosophy of history: a return to things past which are not gone forever but are always ready to return (Calvo Orozco, 2012). The architect's task is to collate all that past in the present: "we shall from time to time find the quays of the future in the harbours of the past, [...] the present becomes tangible by assaulting the future in the past. We shall after all leave here again with plenty of provisions on board and strengthened by what we saw" (Van Eyck, 2008b, p. 310).

Figure 3. Time as constitutive. Playground in Bertelmanplein and design plan of the elements

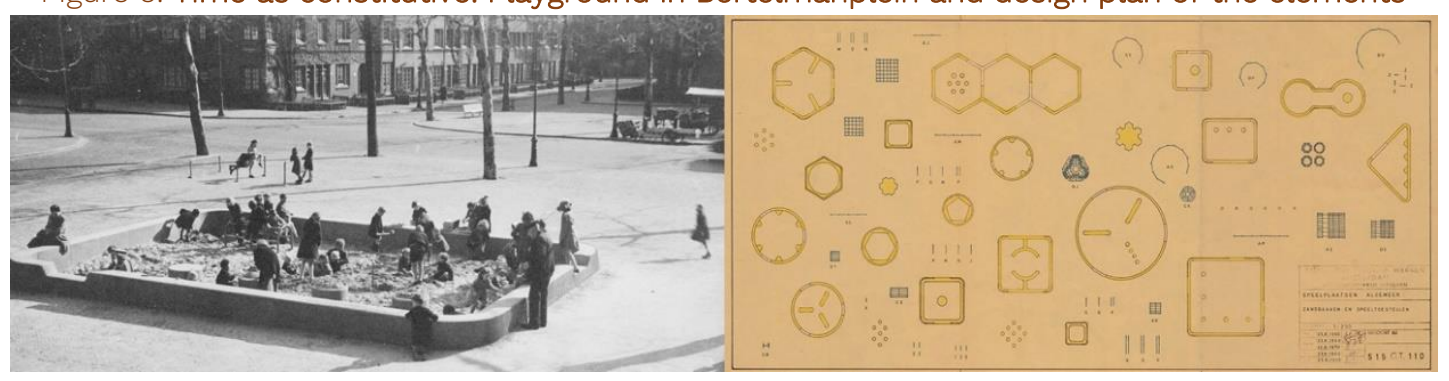

Source: The Aldo and Hannie van Eyck Foundation.

This is where Joyce and Bergson's concept of time has major implications for the concept of history. As Van Eyck admits: "history, you see, is no longer behind us because time no longer Works that way, not since Einstein, Joyce, Mondrian..." (Van Eyck, 2008b, p. 542). On the one hand, we have the duration, the recognition of Joyce's simultaneous, non-successive time (everything is presented at the same time in stream of consciousness), and on the other Einstein's relativity, the idea of a reality with no centre but with multiple possible perspectives.

History is no longer understood as a list of past events which can only be measured within a timeline. When these events are connected one after the other, like links, they explain the present as a necessary consequence of what has come before. However, for Van Eyck, history is a wide range of experiences which directs the interpretation of our present, determining how it can-and should-be transformed. Essential knowledge about human nature and architectural values can be extracted from each of these events. Reconciliation, a term often used by the architect, means "gathering the essential human meaning found in the past" (Van Eyck, 2008b, p. 474) to build an understanding of the nature of human space. Duration (Joyce) and relativity (Einstein) make history become a sort of collective memory, a complex network of events which we can internalise and use, which we can approach with urgency, seeking something we need and had forgotten ${ }^{6}$.

This is not a sentimental or indulgent attitude towards history, but a desire to understand that from the past which exists in the present and continues to be valid. Van Eyck believes that the "simultaneous validity of all cultural patterns" (Van Eyck, 2008a, pp. 121-123), ought to be recognised sine qua non, irrespective of time and place. Bergson's duration somehow forces a different vision of other cultures, rejecting unidirectional progress of time in favour of transparent time and space. Van Eyck terms this accumulation of memories "the gathering body of experience" (Van Eyck, 2008a, p. 120-121). The experience of being related with all occasions and places through a network of memories, desires, and emotional associations gives rise to a feeling of belonging to a place and time: it builds identity. For Van Eyck, architecture should create places enriched by their potential for association, making it necessary to wade into the river of the history of architecture seeking "essential aspects of human space" (Newman, 1961, p. 27).

\footnotetext{
6 The way in which Van Eyck views history can be closely linked to the proposals of materialist philosopher Walter Benjamin, summarised in his Thesis on the philosophy of history (1940).
}

ACE, 14 (42) CC BY-ND 3.0 ES | UPC Barcelona, Spain | Multiculturalism in Post-War architecture: Aldo van Eyck and the 8

Otterlo Circles. DOI: http://dx.doi.org/10.5821/ace.14.42.7033 
Figure 4. Time as Past. Projects by Van Eyck and photographs of his travels

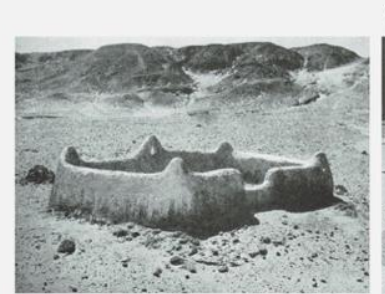

1. El pasado se afronta. .
2. como recopilación de experiencia humana.

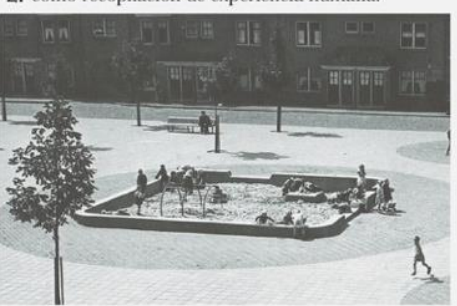

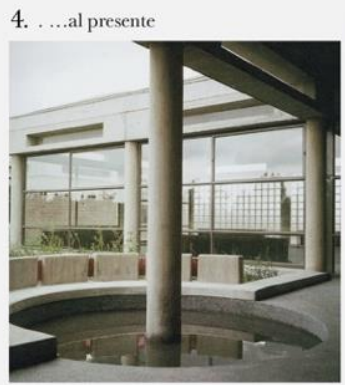

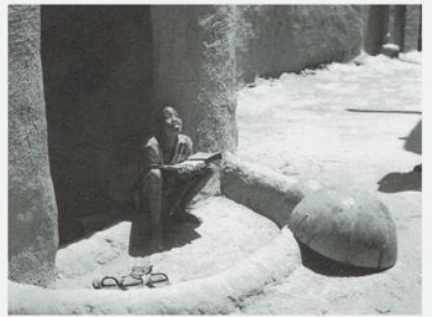

3. Imparte profundidad temporal
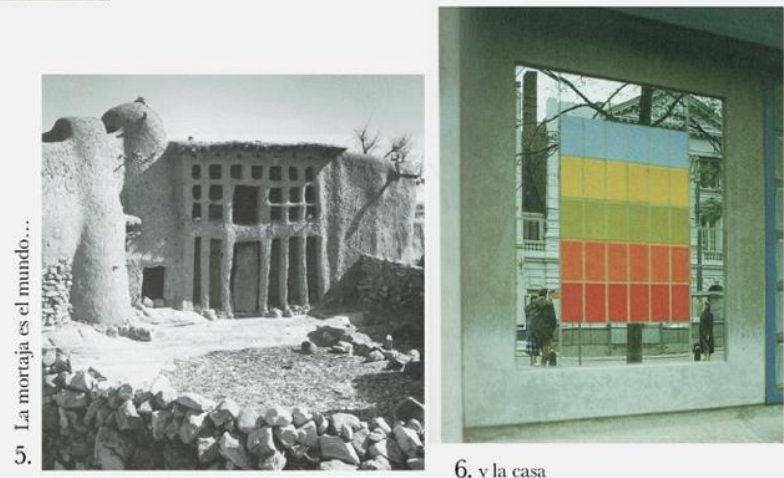

6. yla casi

Timimoudi, sandpit in Jacob Thijsseplein's playground (1949), Amsterdam Orphanage by Raphael Labrunye, trip to Algeria, Dogon house and entrance of the Hubertushuis. Source: The Aldo and Hannie van Eyck Foundation.

Van Eyck's task is about taking responsibility for the past, remembering as the only way to ensure a full existence in the present. However, this does not consist in the repetition of what is remembered, but in bringing it into one's memory to incorporate and translate it with the language of its time. Van Eyck writes that "it is not a repetition but rather a rebirth of the past that implies a creative and constructive process. It is not enough to pick up isolated data of our past; we must really re-collect them, organize and synthesize them, and assemble them into a focus of thought" (Van Eyck, 2008a, p. 77). His approach, therefore, is not historicist, as it involves a process of identification with the old, translating into the new, through which Van Eyck gradually builds his own dictionary of strategies. In fact, several chapters of The Child, the City and the Artist are specifically dedicated to these ideas, especially The Interior of Time (Van Eyck, 2008a).

Thus, the idea of time taken from James Joyce and Carola Giedion-Welcker, along with the early 20th century relativist proposals also applied to anthropology (Benedict, 1967), allow a non-Eurocentric approach to the history of architecture which was indubitably a distinguishing feature of Van Eyck's

ACE, 14 (42) CC BY-ND 3.0 ES | UPC Barcelona, Spain | Multiculturalism in Post-War architecture: Aldo van Eyck and the Otterlo Circles. DOI: http://dx.doi.org/10.5821/ace.14.42.7033 
work. This complex idea of history and architecture, which merges all past and present experiences, of all places, cultures and times, is graphically depicted and summed up (Mayoral Campa, 2014) in the Otterlo Circles - architecture as the reconciliation of multiple pasts.

\section{The three versions of the Otterlo Circles}

"Each culture stresses specific aspects - fundamental solutions - which are universally relevant but which, for various reasons, particular and random, are emphasized whilst others are repressed. Ultimately man suffers from these limitations, from what is overemphasized at the cost of what is omitted and often forgotten. [...] The three images united in the first circle hide no real conflict; nor are their properties incompatible. They completement each other, belong together, and reflect different equally valid aspects of the human personality" (Van Eyck \& Cannon, 1995, p. 4). Although the best-known version of the Circles is that used by Van Eyck in his book The Child, the City and the Artist (Van Eyck, 2008a), there are three versions published over a decade.

The first diagram, the least explicit of the three, is made up of two large circular surfaces (Figure 5). The circle on the left is larger and appears outlined, in recognition of the architect's role, trust in the ability of architecture to transform society. The first NOUS appears in inverted commas, in recognition of the architect, over the second much more general one where the art of this ancestral NOUS represents humanity, with selected pieces from his personal collection of vernacular art. Van Eyck places three elements in each circle and uses two phrases to connect them: "/s architecture going to reconcile basic values" and "Man still breathes in and out, is architecture going to do the same?". A defence of the reconciliation of opposites, the simultaneity of contradictory concepts is graphically represented by the three images in the left-hand circle. Maison Particulière (1923) by Van Doesburg, a symbol of non-Euclidean thought, a dynamic concept of space. The temple of Nike (424 BC) in Athens, one of the wonders of Euclidean thought, classical. Some houses in Aoulef, in the Algerian Sahara, representing the need for shelter, an example of non-Western spontaneous architecture. The Circles propose the reconciliation of these three traditions.

Figure 5. First version of the Otterlo Circles, 1959

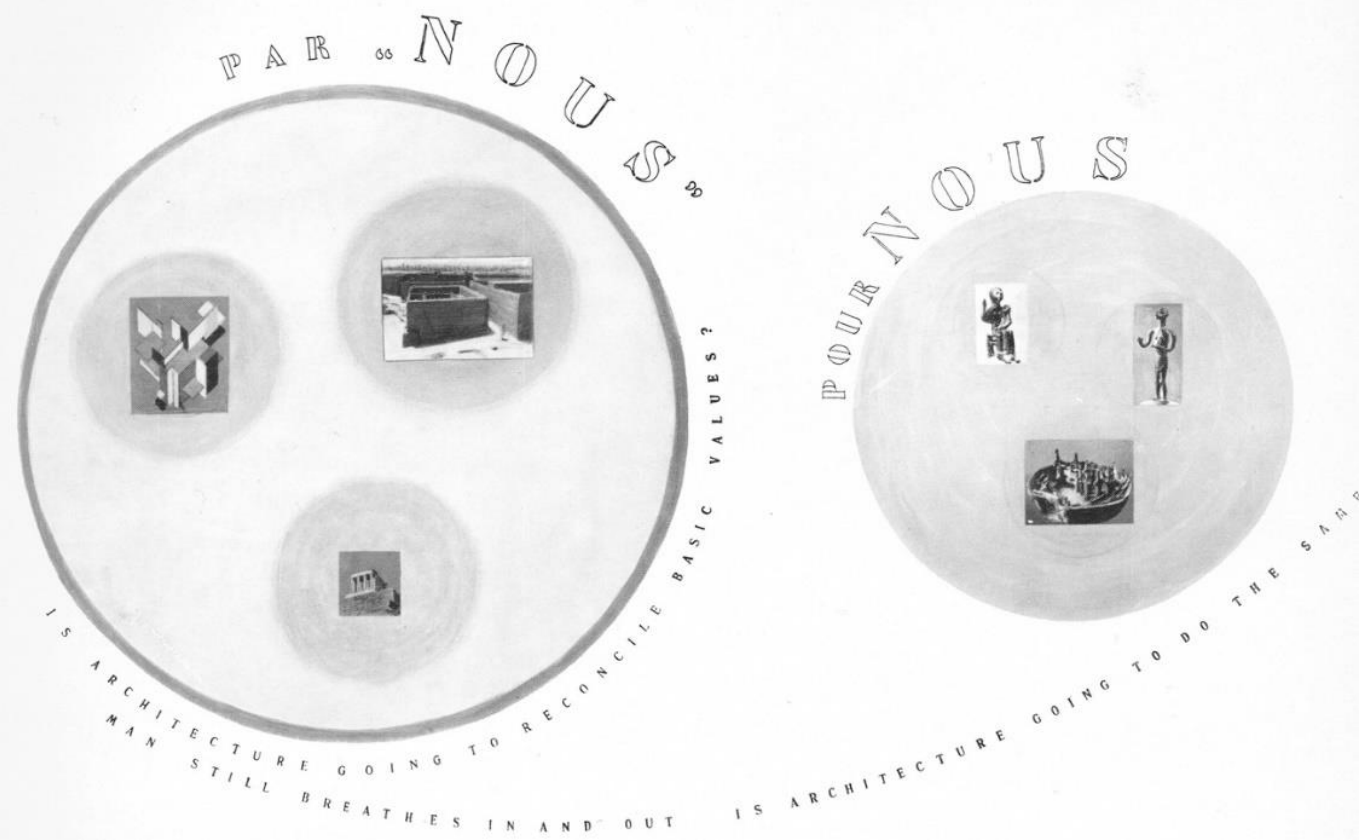

Source: The Aldo and Hannie van Eyck Foundation.

ACE, 14. (42) CC BY-ND 3.0 ES | UPC Barcelona, Spain | Multiculturalism in Post-War architecture: Aldo van Eyck and the 10 Otterlo Circles. DOI: http://dx.doi.org/10.5821/ace.14.42.7033 
Figure 6. Second version of the Otterlo Circles, 1962

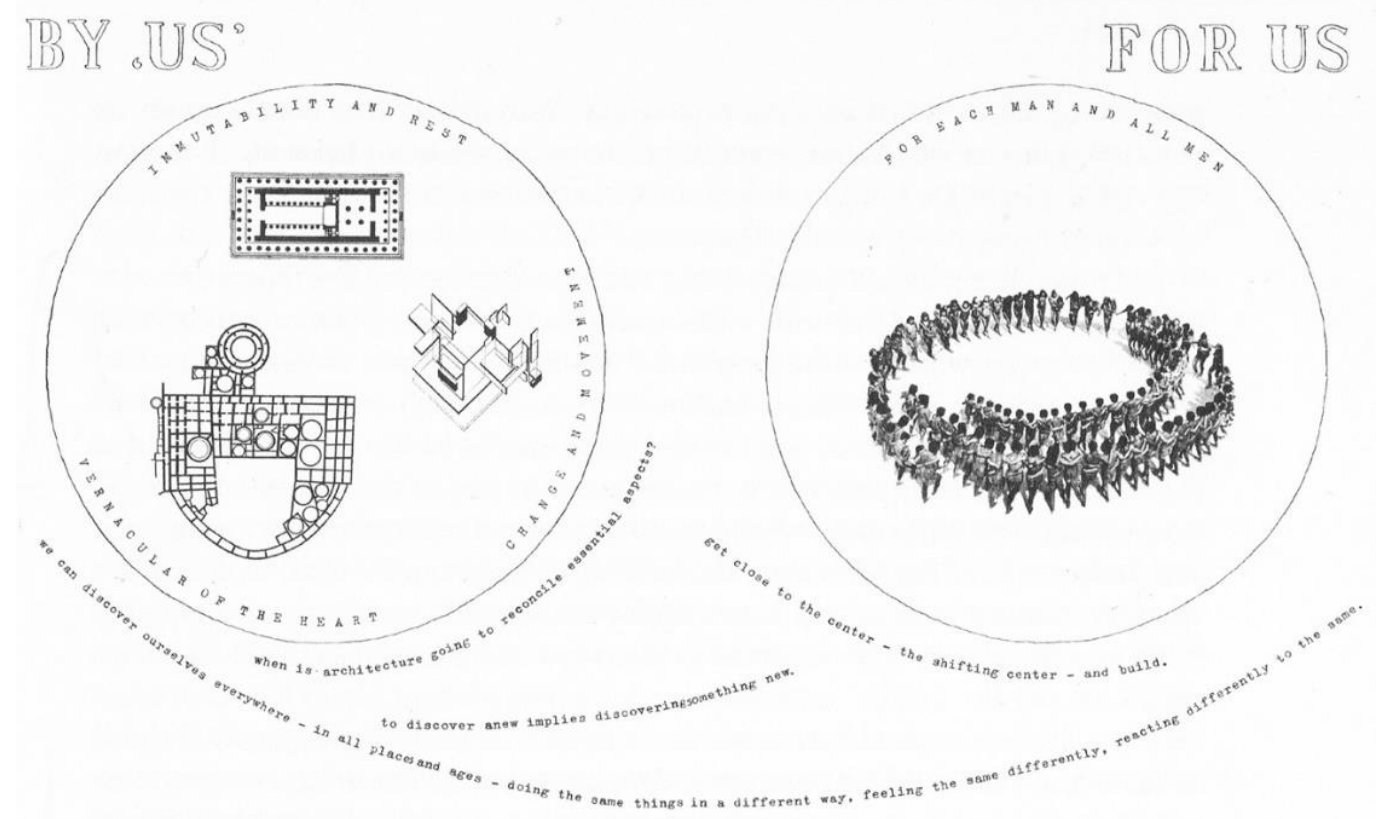

Source: The Aldo and Hannie van Eyck Foundation.

The second, better known, version is that featured in the book The Child, the City, and the Artist in 1962 (Figure 6). The circles are now circumferences and the photographs are drawings, a more specialised medium for the recipient of the message, which can be developed to force relationships between distant bodies (the plan of a city, a temple, and an axonometry). Each of the drawings is captioned: "immutability and rest" for the classical, "the vernacular of the heart" for the primitive, "change and movement" for the modern. For Peter D. E. Clarke, who carried out the most complete conceptual analysis of the diagram in his doctoral thesis, "the inmutability and rest represent the demand for the particularity of the present to be related to timeless values and an ordered cosmos", the "vernacular of the heart imply the demand for the present to gain significance and stability through a relation with the past", and the "change and movement represent the demand for the present to be experienced in the perspective of an open future" (D. E. Clarke, 1985, pp. 53-58).

The Countercomposition by Van Doesburg and the Parthenon appear to be opposed in their definition, while Pueblo Arroyo may be the third element reconciling both opposing tensions. To the right, it is the human community, rather than art, which is now a sign of humanity: "for each man and all men". If we review the writings of Van Eyck, he partly moves away from the arts after the 60s, when his interest is sparked by anthropology, and this is why some lines are changed or added. We can discover ourselves everywhere - in all places and ages - doing the same thing in a different way, feeling the same differently, reacting to the same. This is not so much about reconciling opposites but rather about gaining an anthropological understanding of human beings, following structuralist thought and the texts of Ruth Benedict and Margaret Mead'. This version clearly shows his idea of time and the role of the architect as a collector of experiences, setting the meaning of each drawing, each circle, and each word with greater precision.

\footnotetext{
7 The anthropologists Ruth Benedict (1887-1948) \& Margaret Mead (1901-1978), known for Patterns of Culture (1934) and Coming of Age in Samoa (1928), have been quoted by Van Eyck and are very present in his personal library.
}

ACE, 14. (42) CC BY-ND 3.0 ES | UPC Barcelona, Spain | Multiculturalism in Post-War architecture: Aldo van Eyck and the 11 
The final version (Figure 7), from 1967, simply changes some words and adds nuance to ideas. Extensions of collective behaviour is added inside the first circle for the idea of vernacular; concepts of the mind for the other two: subconscious construction of architecture (anonymous) rather than intellectualised construction (with a known author).

Figure 7. Third version of the Otterlo Circles, 1967

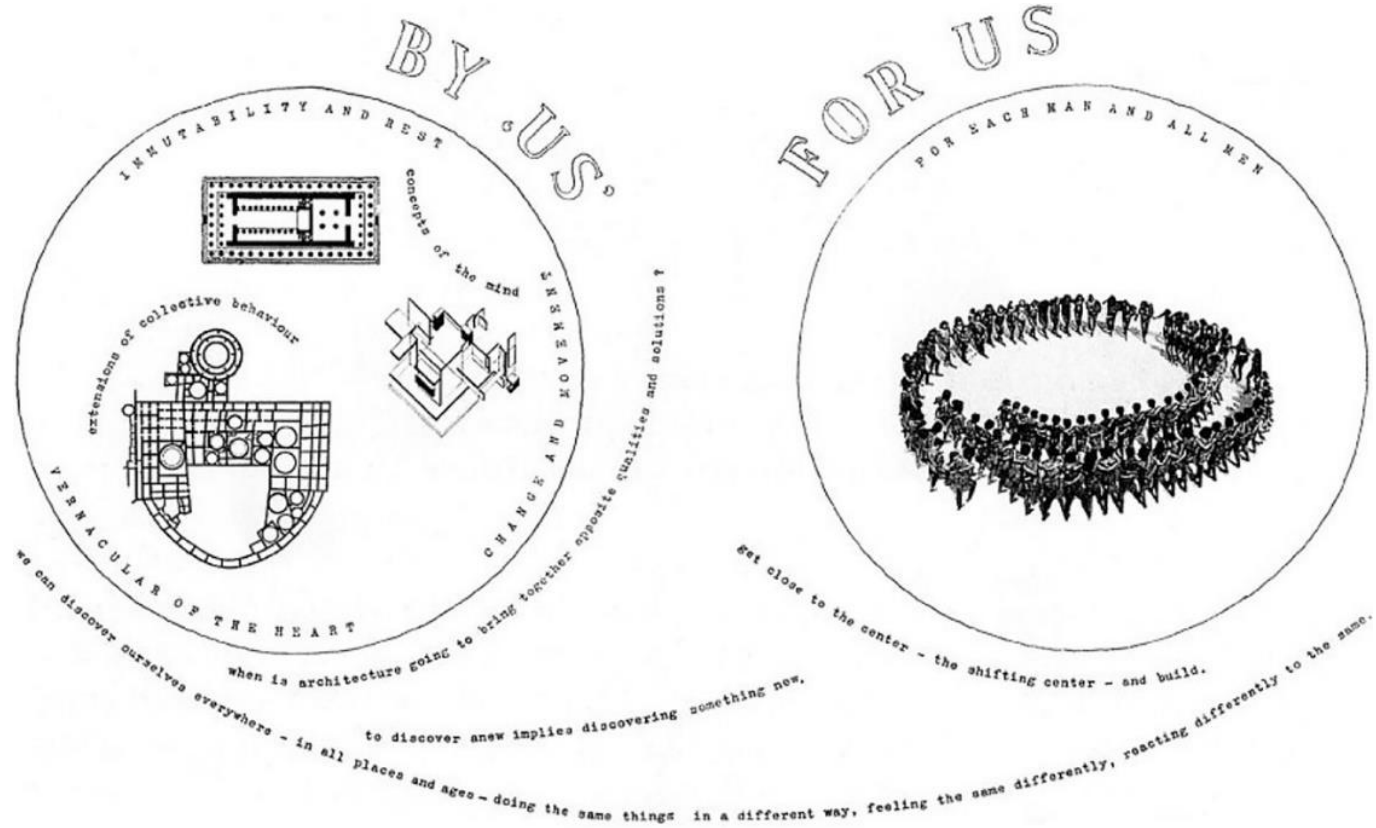

Source: The Aldo and Hannie van Eyck Foundation.

In short, the evolution of the diagram is linked to the evolution of Van Eyck's proposals, with his travels and reading, but most of all it is an attempt to present a more specific proposal, making it readable for the public. The Circles are the graphic representation of the union of complementary aspects which reassemble a fragmented reality. However, they basically represent a new idea of history and time in opposition to the empty and homogeneous time of the idea of progress. The important relationship between Van Eyck's Circles and his idea of time was reinforced by the architect in his first presentation in 1959, when he acknowledged the discoveries of Picasso, Klee, Mondrian and Brancusi; Joyce, Le Corbusier, Schönberg, Bergson, and Einstein (Newman, 1961), before introducing his idea of history:

"The time has come to gather the old into the new; to rediscover the archaic principles of human nature [...] Man is always and everywhere essentially the same. He has the same mental equipment though he uses it differently according to his cultural or social background [...] In each culture there are things universally valid [...] Today we can travel to the remotest places. We can meet 'ourselves' everywhere -in all places and ages - doing the same things in a different way, feeling the same differently, reacting differently to the same [...] When is architecture going to reconcile these basic values?" (Newman, 1961, p. 27).

Proving the importance of the Circles in understanding his projects, the explanation of the first version of the diagram was followed by the first public presentation of the Amsterdam Orphanage. In keeping with this, later studies have used the Otterlo Circles as a framework for the analysis of several of Van Eyck's projects, including the Orphanage (Strauven, 1998) or the expansion of Visser House (Rodríguez y Hernando, 2018). The Otterlo Circles are the synthesis of his theoretical corpus, which allows

ACE, 14 (42) CC BY-ND 3.0 ES | UPC Barcelona, Spain | Multiculturalism in Post-War architecture: Aldo van Eyck and the 12 Otterlo Circles. DOI: http://dx.doi.org/10.5821/ace.14.42.7033 
apparently dissimilar experiences to be brought to the present from the farthest periods of history, in order to be reconciled and assembled. Van Eyck rejects the history of architecture as a continuous line which jumps from one period to another, from one hero to another, focusing only on European architecture. He favours a much more heterodox approach, advocating for a re-collection of experiences and reconciliation of multiple cultures. However, where are all the experiences collected by Aldo van Eyck stored? Is there a version of the circles which can reveal to us the specific sources of his work?

\section{La cuarta versión de los Círculos de Otterlo: la casa como Colección}

"I draw what I make and think from everything I have experienced; from what others in the past and present and everywhere have thought, made and done: the poets I met as a boy; the painters and sculptors; the places I visited near and far..." (Van Eyck, 2008b, p. 152).

One thing that Van Eyck's peers highlight is "his capacity to collect concepts from diverse disciplines" (Ligtelijn et al, 1999, p. 297). Given his studies under Pieter Nicolaas Van Eyck (famous Dutch poet, journalist and essayist) and his close relationship with numerous avant-garde artists, it was not unusual to hear him speak of Klee or Brancusi, Eliot or Blake, seamlessly integrating with his architectural proposals. As early as the 1940s, when he lived in Zurich, Van Eyck began to build up a personal collection of books and works of art, which he acquired or received as gifts from his friends in the CoBrA group. The photographs of the homes he lived in successively, in Zurich until 1946 and in an apartment in Amsterdam from 1948, show the evolution of his personal Collection (Campos Uribe \& Lacomba Montes, 2017). What began as a small group of avant-garde paintings ended up as an enormous collection of vernacular art, often acquired thanks to the auction of modern works (Figure 8). This growing collection was almost certainly one of the main reasons for his move in 1964 to a terraced house in Loenen aan de Vecht, a town $15 \mathrm{~km}$ south of Amsterdam.

Figure 8. Evolution of the Collection, 1940-2018

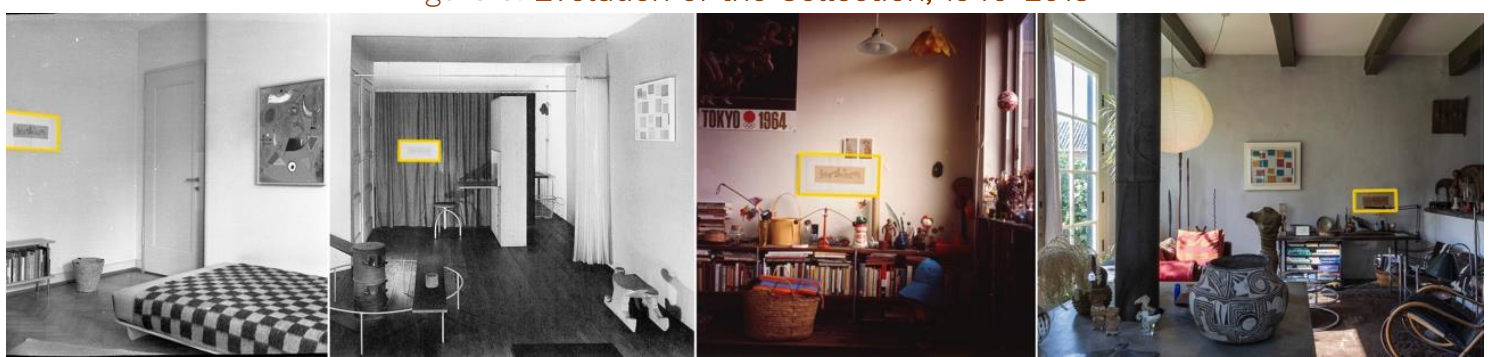

Zurich (1940), Binnenkant (1948), Binnenkant (1950s) and Loenen (2018), following a lithography by Paul Klee. Source: Aldo van Eyck Foundation and photographs by the author.

This residence, a 17th-century building, was transformed by Van Eyck following different architectural strategies into an interior in keeping with his modern thinking. This text examines the house as a collection, the materialisation of the concept of gathering experiences from many different cultures as developed in the Otterlo Circles. It does so through the review of the documents from the archives of the Van Eyck Foundation and the recently published doctoral thesis Aldo van Eyck: le Musée imaginaire (Campos Uribe, 2018a), which examines the project from an architectural perspective.

In the house in Loenen aan de Vecht, currently the headquarters of the Aldo and Hannie van Eyck Foundation, place is presented as a showcase (Déotte, 2013, pp. 41-43), an interior which becomes a universe of object-memories from past and exotic worlds, conserving its own imprints and history: "the asylum where art takes refuge" (Benjamin, 1998, p. 183). Collectors are individuals who respect objects, but through possession they transfigure them eliminating their nature as merchandise and

ACE, 14 (42) CC BY-ND 3.0 ES | UPC Barcelona, Spain | Multiculturalism in Post-War architecture: Aldo van Eyck and the 13 Otterlo Circles. DOI: http://dx.doi.org/10.5821/ace.14.42.7033 
endowing them with the value of their attachment, instead of the value of their use. In this case, Van Eyck transformed oars, doors, bowls, bottles or fabrics into museum suspensions. At the same time, the collector is an individual who, by collecting and inventing art where there is none, tries to reduce the heterogeneity of the world by establishing relationships based on the principle of similarity (Déotte, 2013). The objects, works of art, eventually provide cohesion to the rooms of the house by giving them a name. Thus, the Collection establishes relationships which did not exist, and by bringing strangers in, it provides meaning to objects individually and collectively.

Figure 9. Original plans, original state and proposal, 1964

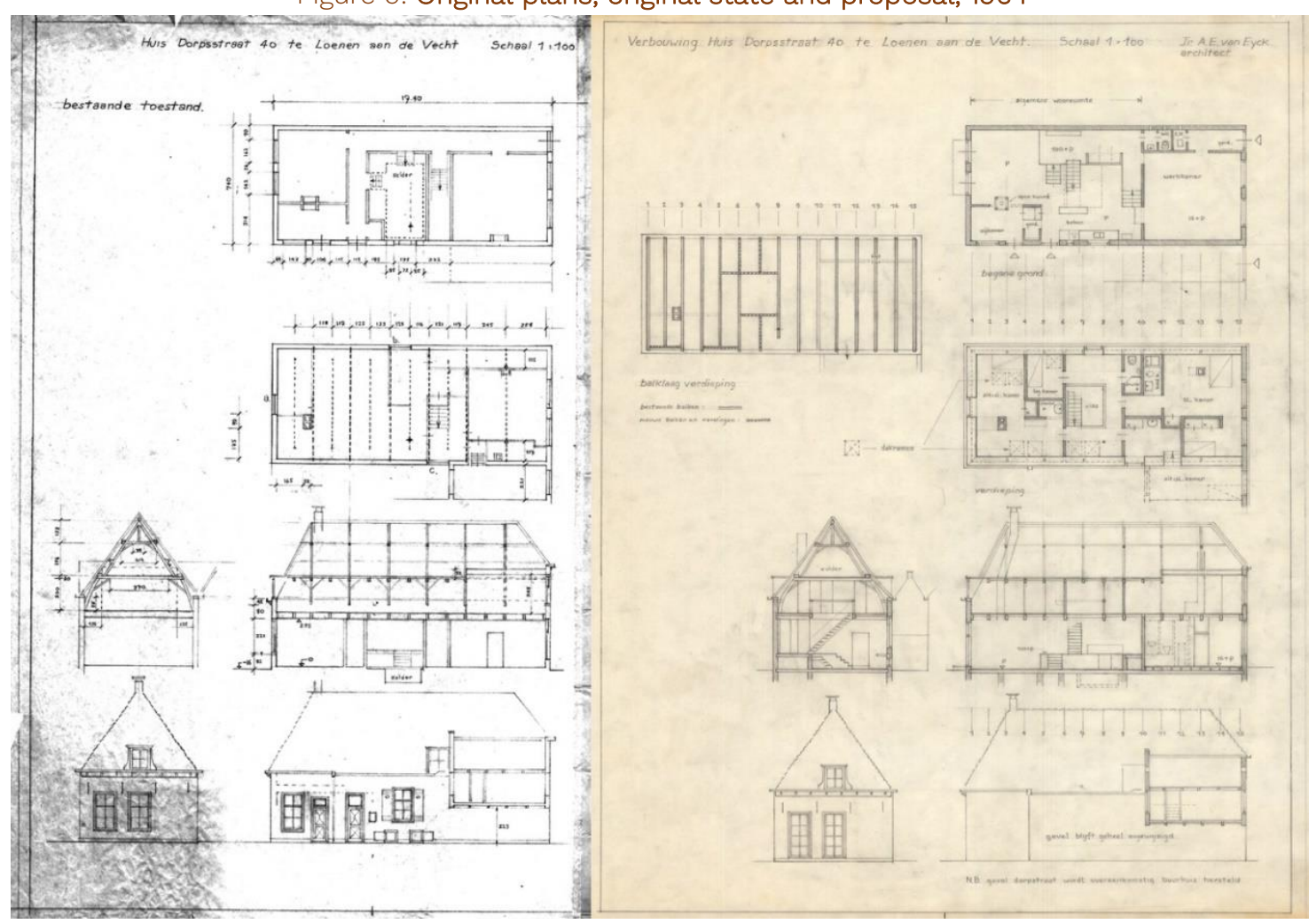

Source: The Aldo and Hannie van Eyck Foundation.

In fact, the transformation of the house itself (Figure 9), and the ground floor in particular, was achieved by incorporating new architectural elements: kitchen benches, staircases, cupboards, and chimneys. All of these were designed one by one and represented in numerous drawings, maintaining their autonomy while establishing relationships with the objects around them. They are positioned in the space of the original construction, acting as separation for spaces, following an architectural strategy usually found in Van Eyck's projects (Figures 10 and 11).

The house therefore appears as the product of the juxtaposition of numerous independent elements built individually through axes and symmetries. However, these elements are not subordinate to a hierarchical order, but form a network of centres which establish reciprocal relationships, making the space more dynamic. All these objects, the centres which make up the house, take on great symbolic value, referring to a cosmology which is unknown to us. The free spaces for use are not others that the voids left between the different objects which make up the home, where the Collection itself builds the space. It is also necessary to approach the objects which are not - strictly speaking architectural (bowls, masks ...) as part of the architecture of the house, in permanent transformation.

ACE, 14 (42) CC BY-ND 3.0 ES | UPC Barcelona, Spain | Multiculturalism in Post-War architecture: Aldo van Eyck and the 


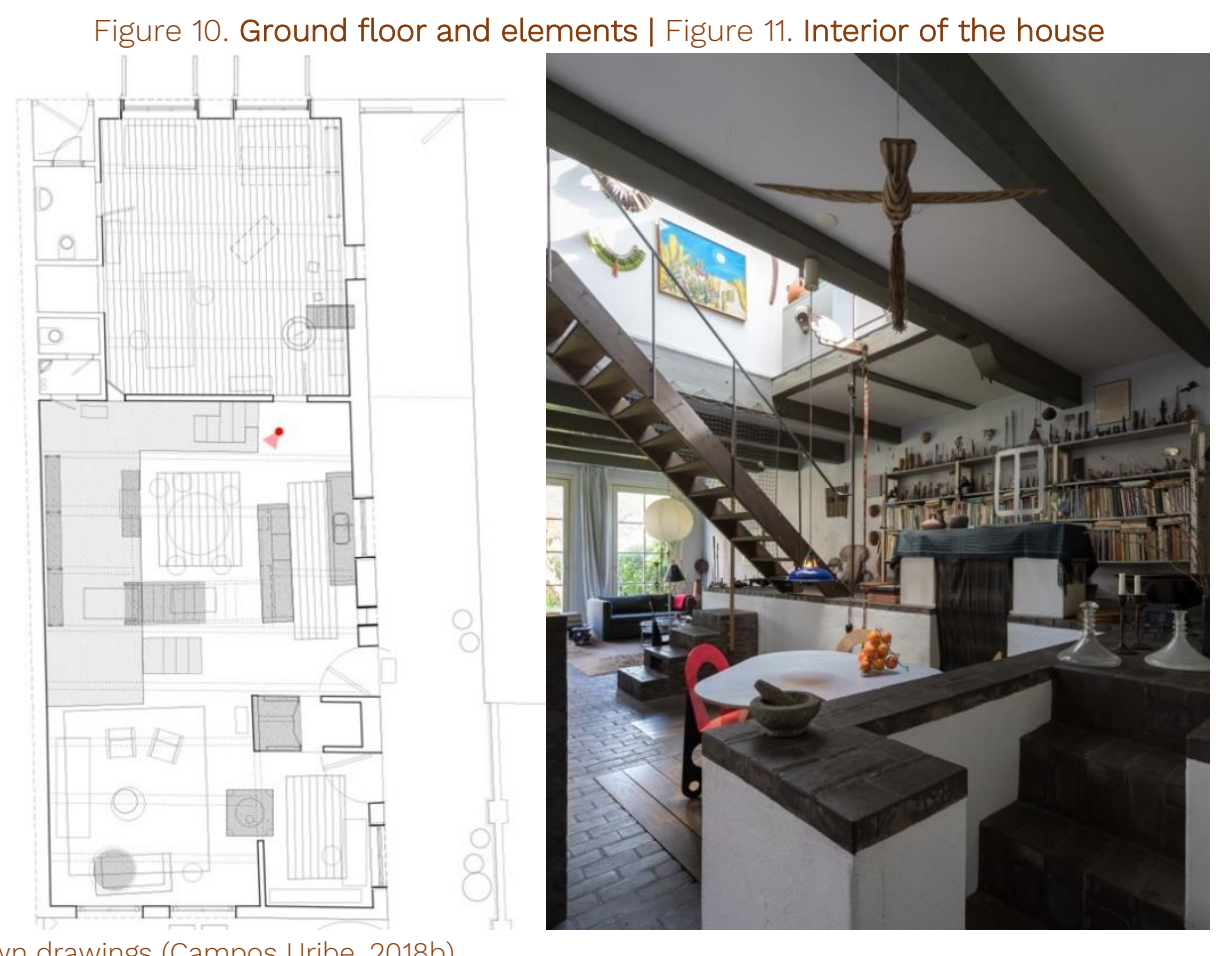

Source: Own drawings (Campos Uribe, 2018b).

Furthermore, the objects in the Collection provide the key to a better understanding of the architectural strategies of the house. We could select a piece from the Collection, Composition with coloured rectangles (1917) by Piet Mondrian, mentioned by Van Eyck in numerous texts, in order to clarify the way in which the new architectural elements added are placed within the original space of the house, establishing relationships of reciprocity and defining the the different nooks and crannies. Van Eyck considered De Stijl to be a major theoretical reference for the construction of his own thinking: "the culture of particular form is approaching its end; the culture of determined relations has begun" (Van Eyck, 2008b, p. 36). Mondrian had attempted to do away with form, creating an abstract composition of pure colours which only reflected universal relations. Each square, in different colours, builds a centre which relates to others within the composition. Analysis can begin or end at any point of the painting. In keeping with this vision, many of Van Eyck's projects are built as a collage of autonomous fragments, basic forms, abstract in the sense of being open to interpretation, centres from which to perceive space.

"I am thinking of the actual corporal place reality of components which are physically tangible as such in that they have a direct human use. A wall, a seat or some steps in which to repose [...] They are not spaces as such but they constitute place in the most direct physical sense. They are tangible points of focus from which space is appreciated" (Van Eyck, 2008a, p. 69).

This architecture, made up of a collage of collected fragments, needs inhabitants to place order in their centres, by relating them to their previous experience and appropriating space as place. Mondrian's painting, identified by the architect as an example of a relational way of practicing architecture, sheds light on the polycentrism found in his own house and other works such as the Playgrounds in Amsterdam (Figure 12). In fact, the impact of the elements - which one by one make up the house and form a network - creates the feeling of place, a space surrounded by elements which hold the family's souvenirs and memories. Hence, the pieces of the Collection should be also approached as fragments in the polycentric composition which is the house itself.

ACE, 14 (42) CC BY-ND 3.0 ES | UPC Barcelona, Spain | Multiculturalism in Post-War architecture: Aldo van Eyck and the 15 Otterlo Circles. DOI: http://dx.doi.org/10.5821/ace.14.42.7033 
Figure 12. Polycentrism in Van Eyck's Playgrounds
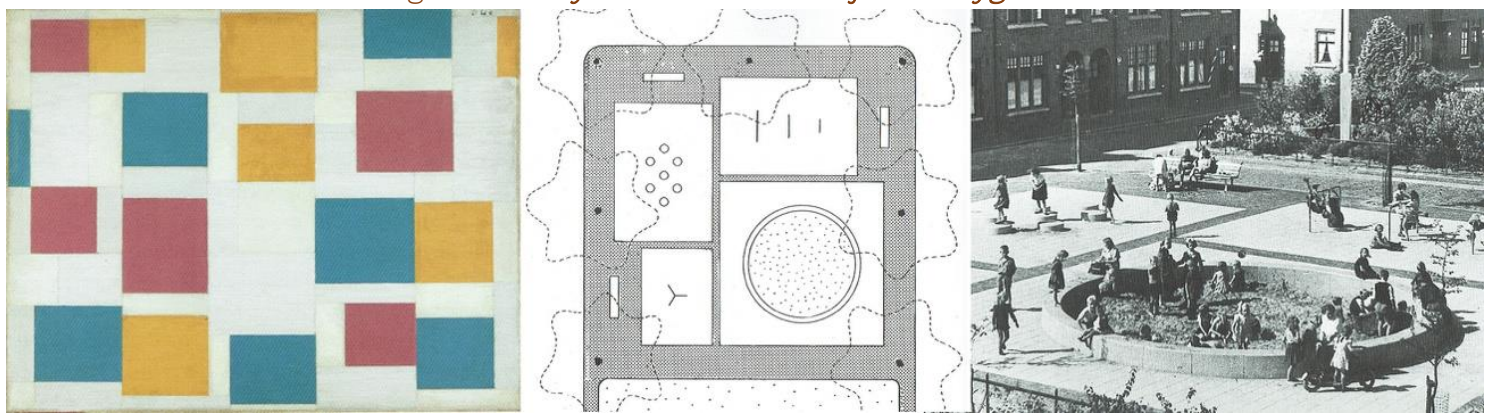

Composition with coloured rectangles, Mondrian. Playground in Zaanhof, 1950. Source: Authors' own using originals from The Aldo and Hannie van Eyck Foundation.

In addition, what characterises an architecture born from the interaction of different centres - the objects of the Collection which make up the house - is that it is enriched by permanently transforming relationships as from 1964 on, when the house was completed, Van Eyck continued to travel and collect objects which he placed in their exact positions (Figure 13). His daughter Tess van Eyck ${ }^{8}$ explains how every new object distorted the position of all the others, making it necessary to find a new balance. Van Eyck had set out to collect the human meaning hidden within each of them, making the lemma of the Otterlo Circles a reality. As the architect slowly transformed the place, creating groups of objects, the place made him into a different architect by expanding his body of experiences. In a vase, Van Eyck found procedures for solving formal problems, in a basket, cosmological concerns, and so on... Objects are deposits of memory, "for a true collector, the background of an item adds up to a magic encyclopaedia whose quintessence is the fate of his object" (Benjamin, 1969, pp. 59-67). Van Eyck explained the objects and their features in many interviews and conferences.

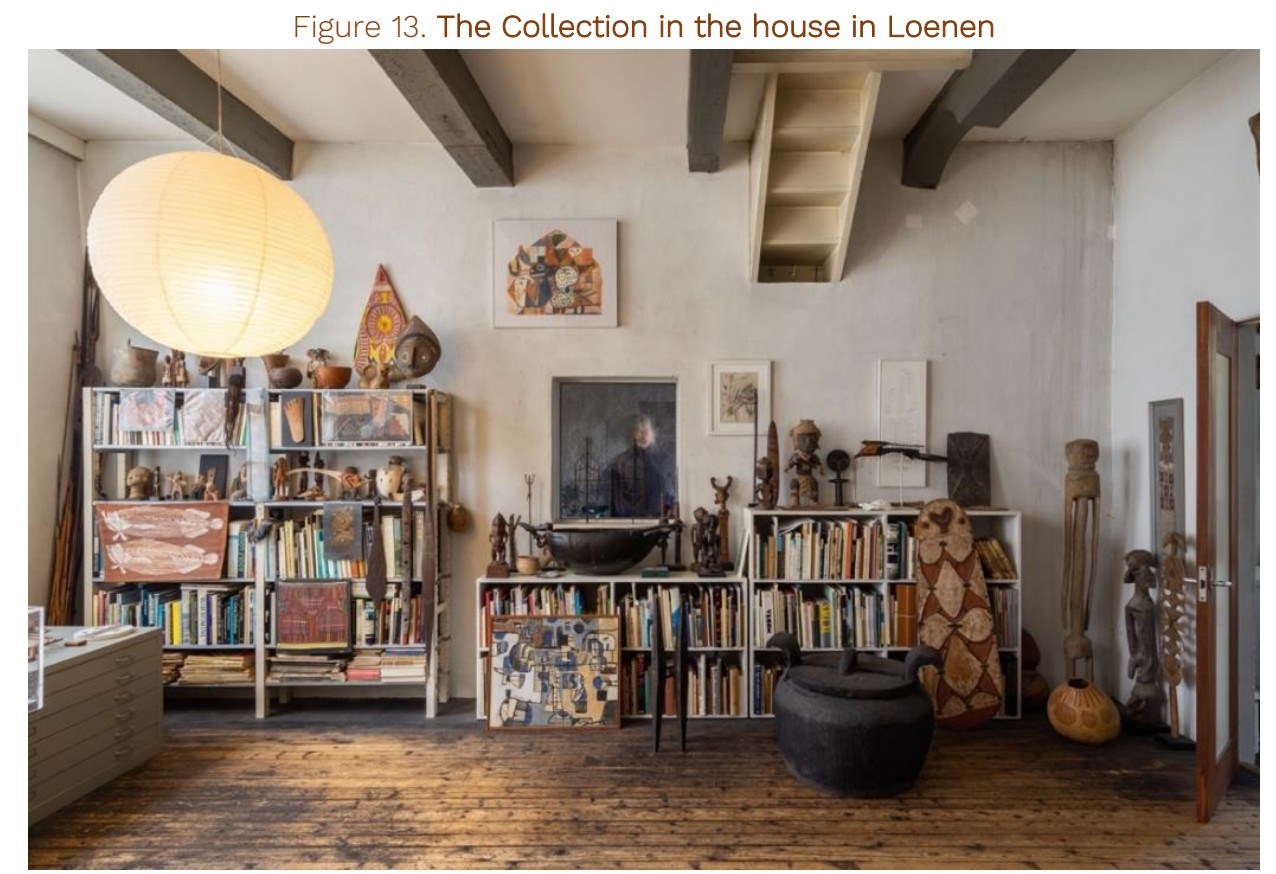

Source: Doctoral thesis (Campos Uribe, 2018a).

\footnotetext{
8 In conversation with the authors.
}

ACE, 14. (42) CC BY-ND 3.0 ES | UPC Barcelona, Spain | Multiculturalism in Post-War architecture: Aldo van Eyck and the 
Although Van Eyck read numerous books on anthropology and ancient art, he interpreted the objects in the search for basic patterns: alterations in symmetry, centrality, existence of multiple centres, etc. He was especially interested in the reconciliation of opposing forms, the configurations of motifs, forms and counter-forms, repetitions and variations. In a conference for the INDESEM seminars held in Rotterdam in 1987, the architect explained some of these objects and identified the key points reinterpreted in his architectural designs. He did not speak about objects seen in photographs, but about pieces he had held in his hands, carefully arranged on his shelves and photographed by himself. In the documentary Markant: Aldo van Eyck (1978), filmed inside his home, he also picks out several objects from the shelves to explain their characteristics (Figure 14). Van Eyck uses these objects and does not only store them in his home driven by a fetishist interest. Instead, he acquires them, analyses and uses them to compile his own dictionary of architectural strategies.

The proof that his multicultural outlook and his Collection are indispensable to understand his work is to be found in the monograph Niet om het even... wel evenwaardig, van en over Aldo van Eyck (1995) - translated "Not the same... but nonetheless, by and about Aldo van Eyck" - written and compiled by Van Eyck himself. The book starts by quoting Benjamin Lee Whorf (structuralist linguist) and especially Franz Boas (anthropologist): "so far as my personal experience goes and so far as I feel competent to judge ethnographical data on the basis of this experience, the mental processes of man are the same everywhere, regardless of race and culture, and regardless of the apparent absurdity of beliefs and customs" (Van Eyck \& Cannon, 1995, p. II). After a selection of travel photographs and the explanation of the Otterlo Circles-before his architectural designs-Van Eyck presents his Collection, showing some of his vernacular and avant-garde art pieces, including DADA poetry books. This section, from page 8 to 15, is introduced by Carola Giedion-Welcker, describing the importance of the past in the work of Van Eyck. The pieces of the family Collection, carefully arranged in the walls and bookshelves of their own home (Figure 15), occupy a privileged position in the narrative used to present and clarify his work, a step which is prior to the architectural work itself.

Figure 14. Van Eyck showing pieces from his Collection

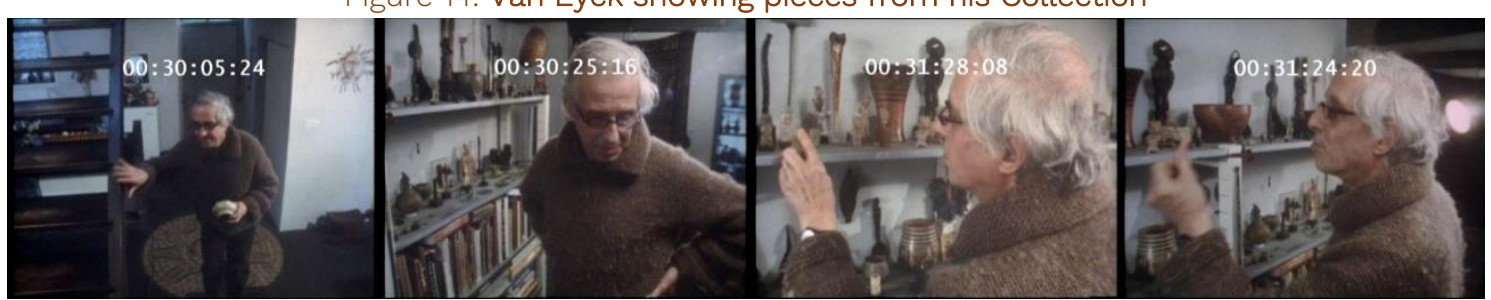

Source: Markant: Aldo van Eyck tv documentary (Kijser, 1978).

Figure 15. Photographs selected by Van Eyck to present his Collection

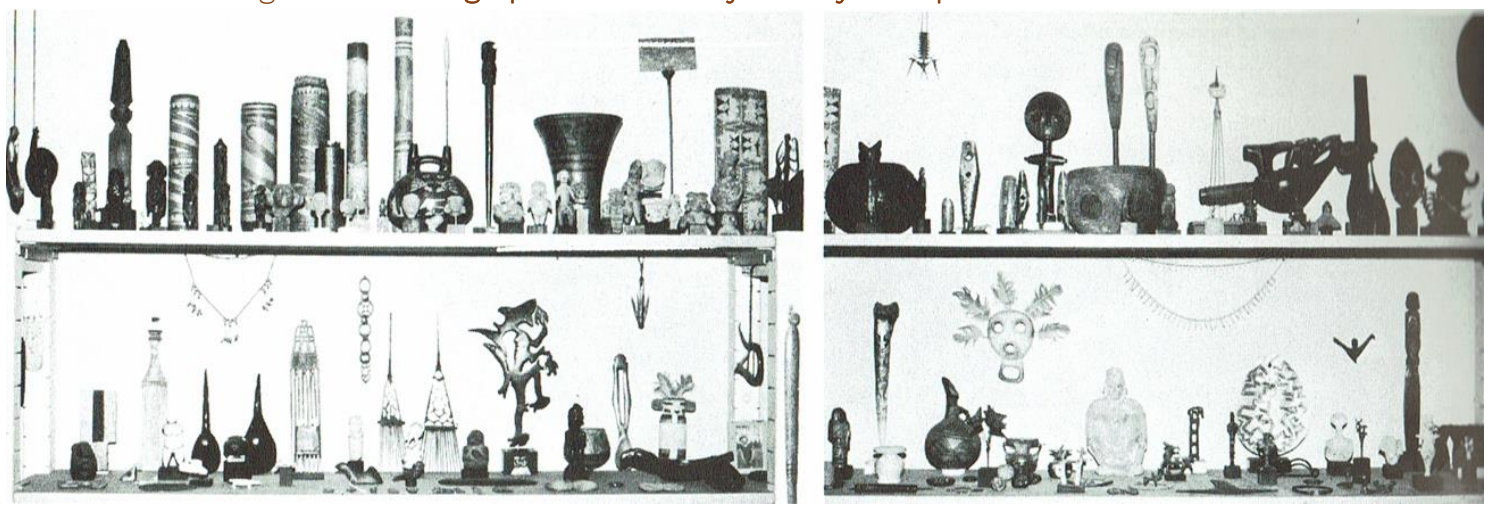

Source: The Aldo and Hannie van Eyck Collection, also in (Van Eyck \& Cannon, 1995, p. 8).

ACE, 14 (42) CC BY-ND 3.0 ES | UPC Barcelona, Spain | Multiculturalism in Post-War architecture: Aldo van Eyck and the 
It is possible to set out on a path through the inside of the house, pausing to look at some of these objects and attempting to identify the reasons why Van Eyck selected them and placed them there. In a small sculpture from the Solomon Islands, Van Eyck finds an equal value between form and counterform: "we tend far too much to think of an active form and to place it on a passive background, or to regard the background as of non-existence [...] But here the openings are almost as active as the form itself" (Van Eyck, 1987, pag. 34). This is the same discussion as that on the interior-exterior equivalence, central to his thinking and easily identified in the Amsterdam Orphanage, 1959, where the exterior is also considered equivalent to the interior. The house also contains a shield from New Guinea which Van Eyck uses as an example of the relationship between vertical and horizontal, "the three is a number that tends inwards, contained within itself [...] four is the first sequential number, it moves outwards, it's horizontal [...] Until you notice the intervals. If you look at three again, you discover there are two spatial intervals and suddenly what was a vertical number becomes binary, with horizontal qualities [...] The four gains a certain verticality, the centre is now open. And that makes a world of difference" (Van Eyck, 1987, 23'38"). This type of number game is a frequent feature of the architect's work, e.g. in the Catholic church in The Hague, 1966 (Figure 16).

Figure 16. Relationship of objects from the house with other projects by Van Eyck
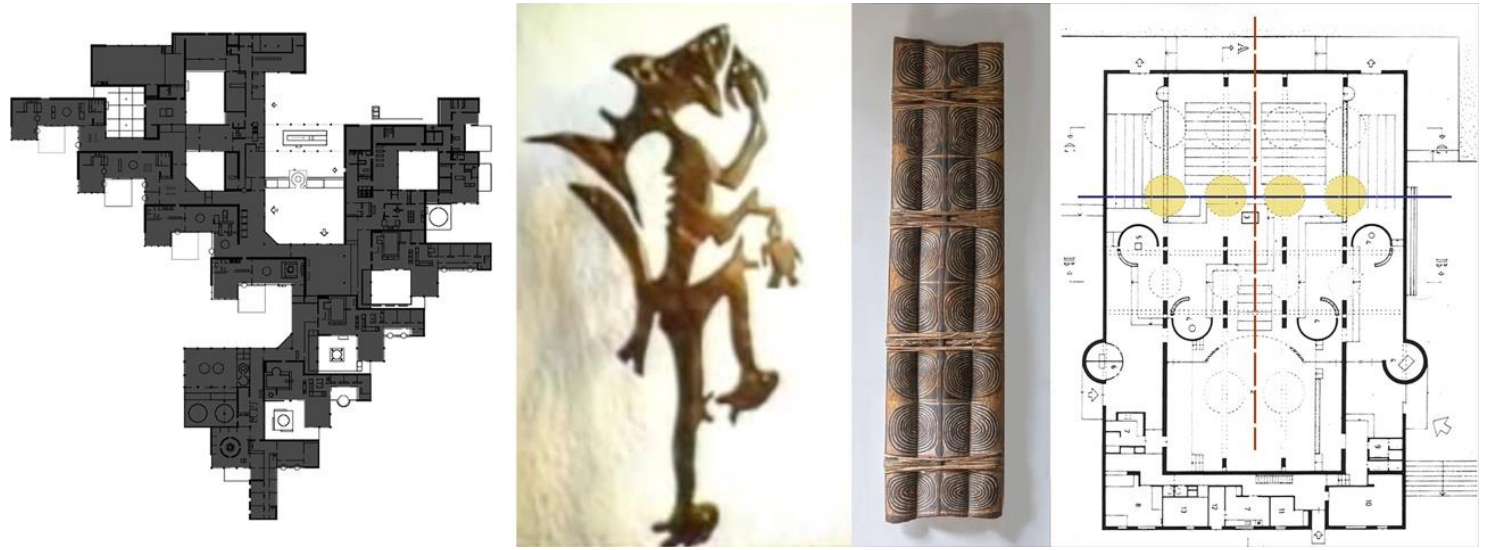

Authors' own. Floor plan of the Amsterdam Orphanage (1959), sculpture from the Solomon Islands, shield from New Guinea and floor plan of the Catholic church in The Hague (1966). Source: Aldo van Eyck Foundation.

The individual examination of the objects from the Collection, in order to identify their relationship to Van Eyck's work, shows the rich potential of the house, capable of opening up new interpretations of his work which highlight the multicultural nature of his thinking ${ }^{9}$. Therefore, while the Otterlo Circles proposed an architecture which learns from all its material forms throughout history, we can say that Van Eyck's house is simply the result of decades worth of his experience as a Collector. This is why we interpret the house and Collection as the true Circles of Van Eyck, the fourth version of the diagram, this time in the form of a material collection of real objects (Figure 17). While earlier we were pointing out an idea of history in which the architect became a collector of experiences, the Van Eyck house includes everything the architect considered important throughout his life, deserving a space on his shelves along with the other objects, collected from all eras, cultures and places: bowls from Indonesia, African shields and masks, poetry and anthropology books, paintings by Constant, Paul Klee, slides from conferences or travel photographs:

\footnotetext{
${ }^{9}$ The Aldo and Hannie Van Eyck Foundation has recently made available a complete catalogue of the artist's art collection, as well as a list from his personal library. It is also possible to consult all his travel photographs and the slides used in his conferences.
}

ACE, 14 (42) CC BY-ND 3.0 ES | UPC Barcelona, Spain | Multiculturalism in Post-War architecture: Aldo van Eyck and the 18 
"Living in this interior crowded with tangible witnesses to every civilization and period, experiencing the simultaneous presence of images originating from the most remote corners of the world and from over five millennia, dwelling in this continuum of symbols in which time and space converge, admiring the huge diversity of these elementary artefacts, touching them, rediscovering them, comparing them, arranging and rearranging them in different groupings: all this forms an inexhaustible source of joy and inspiration for Van Eyck. Contact with these objects carries him almost daily on imaginary journeys to far-off places and times" (Strauven, 1998, pp. 453-454).

Figure 17. Van Eyck's home, forth version of the Otterlo Circles

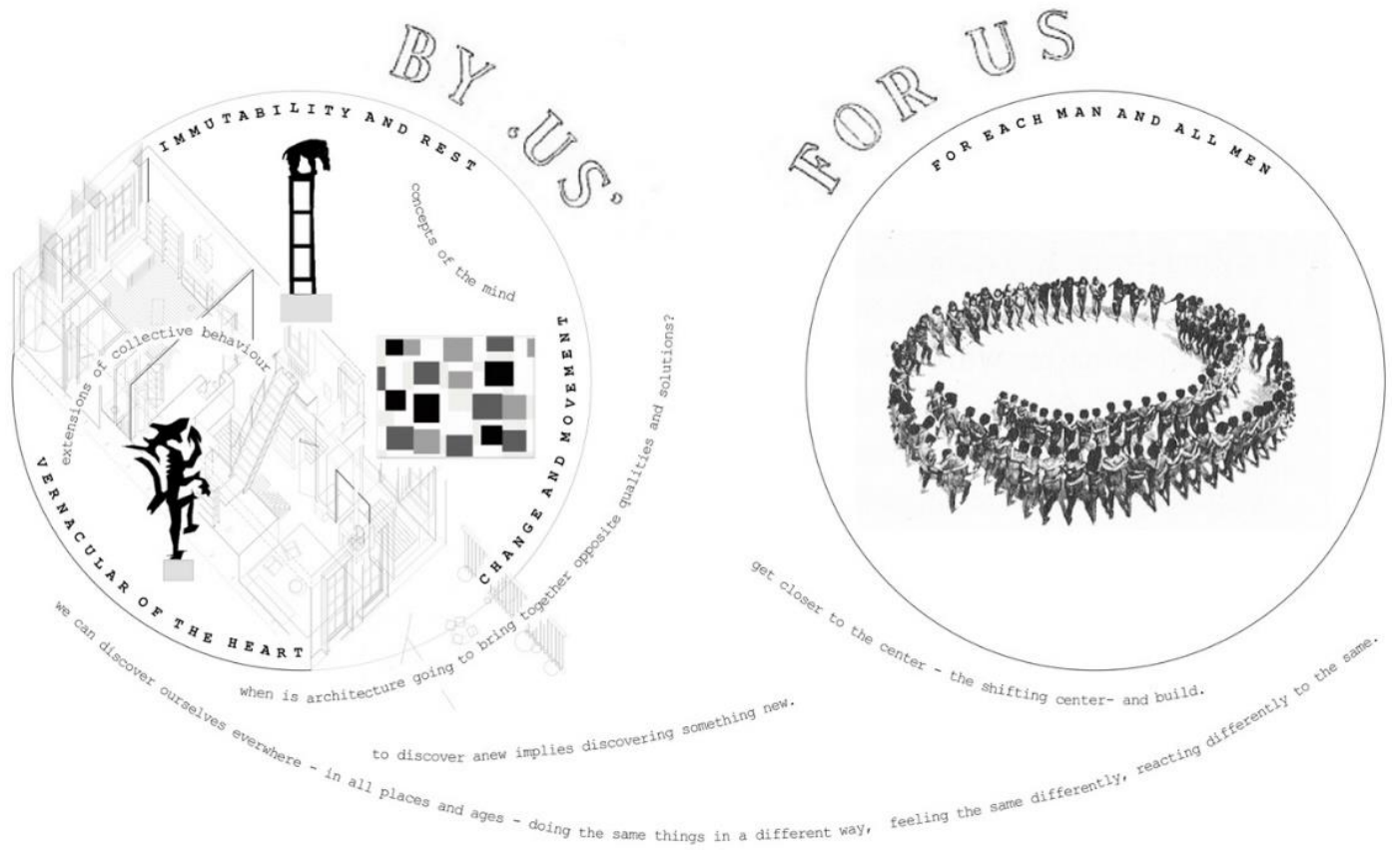

Three objects from the house (classic, modern and vernacular). Source: Authors' own.

In particular, the coexistence of all the objects of such diverse types, from such different cultures, in a single space, selected by a single person, confirms Van Eyck's rejection of functionalist Eurocentrism and his attempt to build a new multicultural and inclusive architecture which can only be explained from a conception of history like that of the Otterlo Circles. This is why the house is now seen as a necessary pitstop to understand the scope of his trajectory. Through the rigorous study of the objects that make up the house, it must be possible to understand his architectural strategies. This is why this paper has explored his home not only as a spatial and constructive proposal, but also as a place where all his interests converge, creating relationships which can explain how his architectural discourse was constructed.

\section{Conclusions}

As an architect from the third generation of the Modern Movement, Aldo van Eyck combines a series of artistic, literary, and architectural traditions, which find their origin in the avant-garde. However, his contribution incorporates a closer look at a far more heterodox past, as a collection of experiences from all cultures, places and times. The Otterlo Circles are an exact graphic representation of this reconciliation of seemingly contradictory aspects, a real opposition to Eurocentrism in favour of an architecture combining multiple cultures, all the experiences of the past, without a tabula rasa. This is not postmodern eclecticism, but an attempt to understand the collected objects/experiences, from

ACE, 14. (42) CC BY-ND 3.0 ES | UPC Barcelona, Spain | Multiculturalism in Post-War architecture: Aldo van Eyck and the 19 Otterlo Circles. DOI: http://dx.doi.org/10.5821/ace.14.42.7033 
which "basic human values" are obtained and used to build a new architecture. It is precisely this idea of time in a relativist context, inherited from Joyce and Bergson, which provides the theoretical foundations to bring the past closer to the present as a current and urgent interpretation. A past full of experience which should guide the active transformation of the present, a basic key underlying his entire theoretical contribution.

In this context, the Van Eyck house in Loenen aan de Vecht is the place where all these experiences collected from the past converge and are available for an analysis of how domesticity, travel, and the act of collecting supported a non-universalist perspective which came to radically transform postwar architectural discourse. The great contribution of Team 10 to architecture lies specifically in the valorisation of what exists, from social relations to geographical contexts and everyday objects. Van Eyck's house shows this double concern, as a careful transformation of an existing building and as a Collection of memories which have been carefully drawn, photographed and documented to be placed at the disposal of anyone wishing to visit the house in virtual form (Figure 18).

Figure 18. Sample from the Collection catalogue

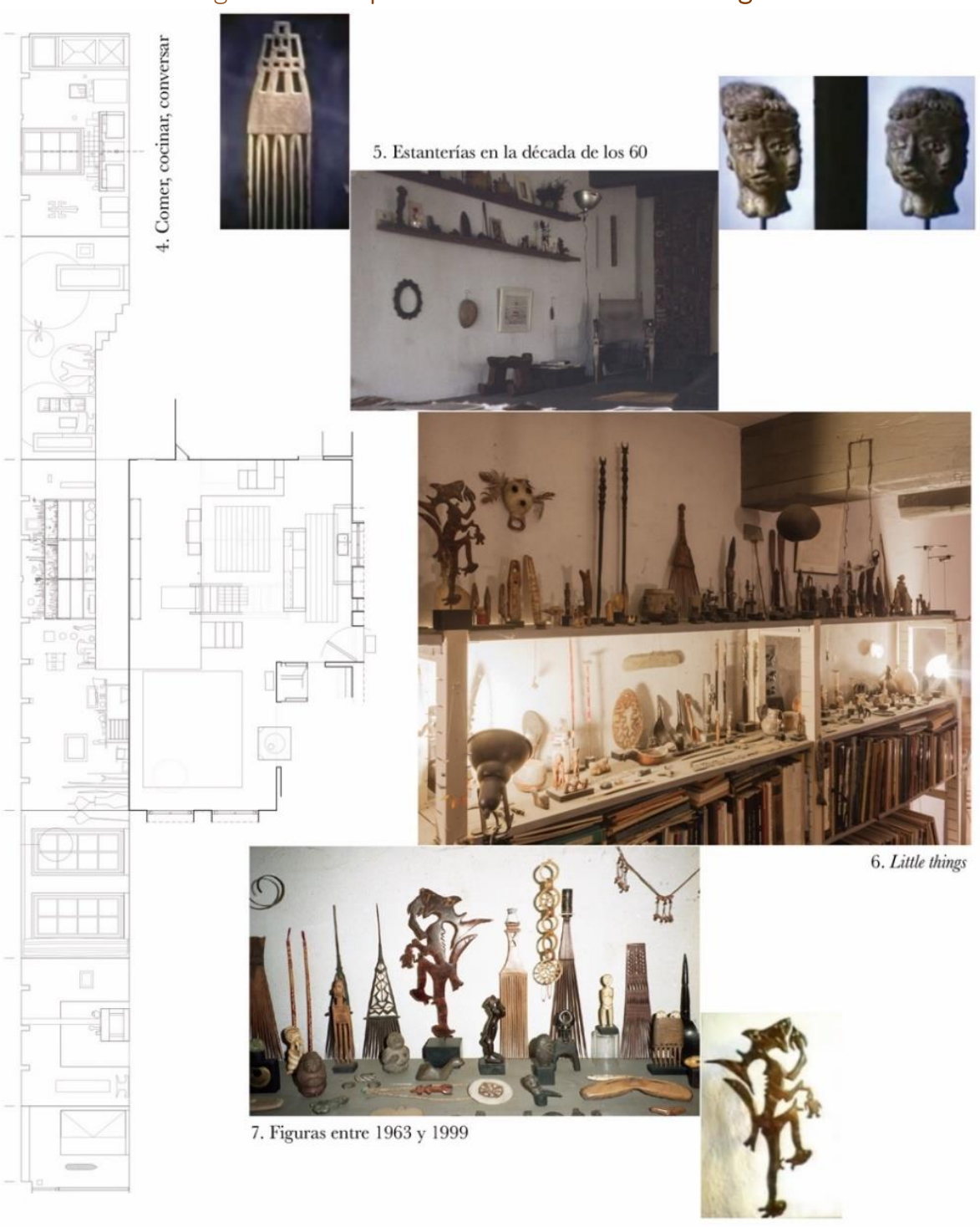

Source: Doctoral thesis (Campos Uribe, 2018a).

ACE, 14. (42) CC BY-ND 3.0 ES | UPC Barcelona, Spain | Multiculturalism in Post-War architecture: Aldo van Eyck and the 
One could continue listing the relationships between the objects collected by the architect and his projects. Following the recent discovery of the house, this paper has attempted to construct a theoretical foundation which makes it possible to examine it as a primary source for Van Eyck's architecture. The qualitative analysis of one individual's home and its contents as a key to a specific way of thinking has not been attempted before, but still promises to be fruitful in light of very recent publications on the field of Architectural Anthropology (Stender 2016). Hence, the driving forces for his projects should not be sought only in his writings or colleagues, as has been the case until now, but particularly in his house in Loenen aan de Vecht, in his personal collection of experiences. Only the fourth version of the Otterlo Circles, which has just been made known and is available at the Foundation for rigorous analysis, will shed light on his proposals, his understanding of the past and his enigmatic projects. Quoting Picasso, Van Eyck presents a past which can be approached with urgency and without prejudice, as a collection of experiences which must support the act and teaching of architectural design:

"The artist is a receptacle of emotions coming from anywhere: from the sky, the earth, a scrap of paper, a passing figure or a spider's web. That is why one should not discriminate between things. For them there are not quarters of nobility" (Van Eyck, 2008a, p. 38).

\section{Acknowledgements}

This research has been funded with a Predoctoral Fellowship by the Department of Education, Research and Culture of the Valencian Community. The collaboration of the Aldo and Hannie van Eyck Foundation, especially through Tess van Eyck (head), has also been essential to access the documents and the architect's own home.

\section{Authorship}

The basic materials used in this research originated during Alejandro Campos' (1st author) Ph.D., the researcher most familiar with the work and thinking of Aldo van Eyck that had the most prominent participation in the drafting of sections 2, 3 and 4. María de Miguel ( $2^{\text {nd }}$ author) has developed the Introductory section (section 1), presenting Team 10 and the historical context in which Van Eyck's work took place. Paula Lacomba (3 ${ }^{\text {rd }}$ author) has contributed to the drafting of sections 2, 3 and 4, developed graphic materials (especially Figures 12, 16 and 17), and has played an essential role in the structure of the article, as she suggested the approach to Van Eyck's house as a Collection, crucial for the essay after peer-review. Jordi Martínez ( $4^{\text {th }}$ author) firstly proposed the analysis of the house as the fourth Otterlo Circle, and has contributed especially to the development of section 2. All authors have participated in all stages of the essay - structure, writing, conclusions, selection of graphic material and review process - in a very enriching co-writing process that has improved greatly the approach and the accuracy of the paper.

Conflict of interest: Authors declare that there is no conflict.

\section{Bibliography}

Benedict, R. (1967). El hombre y la cultura. Buenos Aires, Argentina: Editorial Sudamericana.

Benjamin, W. (1969). Illuminations. New York: Schocken Books.

ACE, 14 (42) CC BY-ND 3.0 ES | UPC Barcelona, Spain | Multiculturalism in Post-War architecture: Aldo van Eyck and the 21 Otterlo Circles. DOI: http://dx.doi.org/10.5821/ace.14.42.7033 
Benjamin, W. (1998). Poesía y capitalismo: Iluminaciones I/. Madrid: Taurus.

Bergson, H. (1989). Essai sur les données inmédiates de la conscience. Paris, France: Félix Alcan.

D. E. Clarke, P. (1985). The Writings of Aldo Van Eyck: A Modernist Sensibility Introduced Into Architecture (Doctoral Thesis). University of Bristol, Bristol.

Calvo Orozco, D. E. (2012). La filosofía de la historia de Giambattista Vico. Estudios Bolivianos, 17, 4359.

Campos Uribe, A. \& Lacomba Montes, P. (2017). A Photographic reconstruction of Aldo van Eyck's own House: fragment and collage. Zarch: Journal of interdisciplinary studies in Architecture and Urbanism, 9, 132-145. DOI: https://doi.org/10.26754/ojs-zarch/zarch.201792272

Campos Uribe, A. (2018a). Aldo van Eyck: Le Musée Imaginaire. Aldo and Hannie van Eyck's house in Loenen aan de Vecht (Doctoral Thesis). Universitat Politècnica de València, València. DOI: https://doi.org/10.4995/thesis/10251/111845

Campos Uribe, A. (2018b). How to draw Aldo van Eyck's house in Loenen. Rita: Revista Indexada de Textos Académicos, 9, 126-133. DOI: https://doi.org/10.24192/2386-7027(2018)(v9)(08)

Déotte, J. (2013). La Ciudad Porosa: Walter Benjamin y La Arquitectura. Santiago de Chile: Metales Pesados.

Giedion-Welcker, C. (1928). On Ulysses by James Joyce. Neue Schweizer Rundschao, XXI, 18-32.

Giedion-Welcker, C. \& Jolas, E. (1930). Work in progress: a linguistic experiment by James Joyce. Transition, 19-20, 174-183.

Ligtelijn, V. (Ed.) et al. (1999). Aldo van Eyck: Works 1944-1999. Switzerland: Birkhauser Verlag.

McCarter, R. (2018). Aldo van Eyck and Louis I. Kahn: Parallels in the Other Tradition of Modern Architecture. Zarch: Journal of interdisciplinary studies in Architecture and Urbanism, 10, 44-61. DOI: https://doi.org/10.26754/ojs zarch/zarch.2018102929

Mayoral Campa, E. (2014). Shared thoughts: Aldo van Eyck, the CoBrA group, and Art. Proyecto, progreso y arquitectura, 11, 64-75. DOI: https://doi.org/10.12795/ppa.2014.111.05

Kijser, J. (Director). (1978). Markant: Aldo van Eyck [TV documentary]. Netherlands: Max Appelboom Producties.

Newman, O. (Ed.). (1961). CIAM '59 in Otterlo. Stuttgart, Germany: Karl Krämer Verlag.

Pedret, A. (2001). CIAM and the emergence of Team 10 Thinking, 1945-1959 (Doctoral Thesis). Massachusetts Institute of Technology, Massachusetts.

Risselada, M. \& Van den Heuvel, D. eds. (2006). Team 10: In Search of a Utopia of the Present 19531981. Netherlands: NAI Publishers.

ACE, 14 (42) CC BY-ND 3.0 ES | UPC Barcelona, Spain | Multiculturalism in Post-War architecture: Aldo van Eyck and the 22 Otterlo Circles. DOI: http://dx.doi.org/10.5821/ace.14.42.7033 
Rodríguez García, A. y Hernando de la Cuerda, R. (2018). The circle without center: modern, classical and vernacular tradition in the Visser House by Aldo van Eyck. Zarch: Journal of interdisciplinary studies in Architecture and Urbanism, 10, 74-87. DOI: https://doi.org/10.26754/ojs zarch/zarch.2018102932

Stender, M. (2017). Towards an Architectural Anthropology - what architects can learn from anthropology and vice versa. Architectural Theory Review, 21(1), 27-43. DOI: https://doi.org/10.1080/13264826.2016.1256333

Strauven, F. (1998). Aldo van Eyck: The Shape of Relativity. Amsterdam, Netherlands: Architecture \& Natura Press.

Van Eyck, A. (1987). [jaschoonman]. (2011, April 23). Indesem 87: Aldo van Eyck [Youtube video]. Retrieved from https://www.youtube.com/watch?v=Uf7RygXIYmM

Van Eyck, A. \& Cannon, H. (1995). Nieto $m$ hete ven... wel evenwaardig, van en over Aldo van Eyck. Amsterdam, Netherlands: Uitgeverij van Gennep B.V.

Van Eyck, A.; Straven, F. \& Ligtelijn, V. (Eds.). (2008a). The Child, the City and the Artist: and essay on architecture and the in-between realm. Amsterdam, Netherlands: Sun Publishers.

Van Eyck, A.; Straven, F. \& Ligtelijn, V. (Eds.). (2008b). Collected articles and other writings 1947-1998. Amsterdam, Netherlands: Sun Publishers. 